\title{
MICE WITH MONOALLELIC GNAO1 LOSS EXHIBIT REDUCED INHIBITORY SYNAPTIC INPUT TO CEREBELLAR PURKINJE CELLS
}

\section{Running title: Gnao1 model shows reduced inhibition in cerebellum}

Huijie Feng ${ }^{1}$, Ph.D., Yukun Yuan¹, M.D., Ph.D., Michael R. Williams², Ph.D, Alex J. Roy¹, Jeffery Leipprandt ${ }^{1}$, M.S., Richard R. Neubig ${ }^{1 *}$, M.D., Ph.D.

1. Department of Pharmacology \& Toxicology, Michigan State University, East Lansing, MI

2. Department of Pediatrics and Human Development, Michigan State University, Grand Rapids, $\mathrm{Ml}$

HF, YY, AJR, WJR, and RRN Designed Research; WJR provided unpublished reagents; HF, AJR and JL Performed Research; HF Analyzed Data; HF Wrote the paper; YY, AJR, WJR, and RRN Edited the paper.

${ }^{*}$ Corresponding author

Richard. R. Neubig, M.D., Ph.D.

Tel: 001-517-353-7145

Fax: 517-353-8915

E-mail address: rneubig@msu.edu

Mailing address: 1355 Bogue Street B440 Life Science Building, East Lansing, MI, 48824, US

Number of Figures: 10

Number of Tables: 0

Number of words for Abstract: 200

Number of words for Significance Statement: 81

Number of words for Introduction: 643

Number of words for Discussion: 598

Authors report no conflict of interest.

Funding sources: Support for this project was from The Bow Foundation and the MSU Clinical Translational Science Institute; support for HF was from the American Epilepsy Society; Support for AJR from MSU ASPET SURF 


\section{Abstract}

GNAO1 encodes $\mathrm{G} \alpha_{0}$, a heterotrimeric $\mathrm{G}$ protein alpha subunit in the $\mathrm{G}_{\mathrm{i} / \mathrm{o}}$ family. In this report, we used a Gnao1 mouse model "G203R" previously described as a "gain-of-function" Gnao1 mutant with movement abnormalities and enhanced seizure susceptibility. Here, we report an unexpected second mutation resulting in a loss-of-function $\mathrm{G} \alpha_{\mathrm{o}}$ protein and describe alterations in central synaptic transmission.

Whole cell patch clamp recordings from Purkinje cells (PCs) in acute cerebellar slices from Gnao1 mutant mice showed significantly lower frequencies of spontaneous and miniature inhibitory postsynaptic currents (sIPSCs and mIPSCs) compared to WT mice. There was no significant change in sEPSCs or mEPSCs. Whereas mIPSC frequency was reduced, mIPSC amplitudes were not affected, suggesting a presynaptic mechanism of action. A modest decrease in the number of molecular layer interneurons was insufficient to explain the magnitude of IPSC suppression. Paradoxically, $\mathrm{G}_{\mathrm{i} / \mathrm{o}}$ inhibitors (pertussis toxin), enhanced the mutantsuppressed mIPSC frequency and eliminated the difference between WT and Gnao1 mice. While $\mathrm{GABA}_{B}$ receptor regulates mIPSCs, neither agonists nor antagonists of this receptor altered function in the mutant mouse PCs. This study is the first electrophysiological investigation of the role of $\mathrm{G}_{\mathrm{i} / \mathrm{o}}$ protein in cerebellar synaptic transmission using an animal model with a lossof-function $\mathrm{G}_{\mathrm{i} / \mathrm{o}}$ protein. 


\section{Significance Statement}

This is the first report on the electrophysiological mechanisms of a movement disorder animal model with monoallelic Gnao1 loss. This study illustrates the role of $G \alpha_{\circ}$ protein in regulating GABA release in mouse cerebellum. This study could also facilitate the discovery of new drugs or drug repurposing for GNAO1-associated disorders. Moreover, since GNAO1 shares pathways with other genes related to movement disorders, developing drugs for the treatment of GNAO1-associated movement disorders could further the pharmacological intervention for other monogenic movement disorders. 


\section{Introduction}

GNAO1 encodes the a subunit of a heterotrimeric $\mathrm{G}$ protein, $\mathrm{G}_{\mathrm{o}}$, the most abundant membrane protein in the brain. It participates in multiple neural signaling pathways (Jiang \& Bajpayee, 2009). The $\mathrm{G}_{\mathrm{o}}$ protein functions in a broad range of signaling pathways including inhibition of cAMP production (Sunahara \& Taussig, 2002), Gßy-mediated inhibition of synaptic vesicle release (Zurawski et al., 2017), suppression of $\mathrm{N}$ - and P/Q-type calcium channelmediated currents (Ikeda, 1996), and stimulation of G-protein regulated inward rectifying potassium (GIRK) channels (Zhang, Dickson, \& Doupnik, 2004). Mutations in GNAO1 were found in early onset epileptic encephalopathy (DEE17; OMIM\#615473; Nakamura et al., 2013) and neurodevelopmental disorder with involuntary movements (NEDIM; OMIM\#617493), a rare neurogenetic disorder, characterized by early onset of hypotonia, movement disorder and developmental delay. A genotype-phenotype correlation of GNAO1-associated neurological disorders, based on $\mathrm{G}_{\circ}$ 's inhibition of cAMP production, showed that loss-of-function (LOF) and partial-loss-of-function (PLOF) GNAO1 mutations are mainly associated with epilepsy, while the gain-of-function (GOF) and normal-function (NF) mutations are generally found in movement disorder patients (Feng et al., 2017). A mouse model with a knock-in GOF mutation G203R was reported (Feng et al., 2019). However, based on new genotyping data for the Gnao1 G203R mutant mice, we have discovered a second mutation within the Gnao1 gene. The second mutation disrupts a splice site and likely results in a haploinsufficient LOF allele for Gnao1. These mice were previously shown to exhibit movement abnormalities, assessed in behavioral tests 
including RotaRod, grip strength, and DigiGait, and showed increased sensitivity to pentylenetetrazol (PTZ) kindling (Feng et al., 2019).

To examine the possible mechanisms of movement abnormalities of the Gnao1 mutant mice, we examined changes in spontaneous synaptic responses in Purkinje cells (PCs) in acute cerebellar slices isolated from WT and Gnao1 mutant mice using whole-cell patch clamp recording techniques.

The cerebellum has long been known for its critical regulation of motor coordination; its role in ataxia has been well-studied (Buijsen, Toonen, Gardiner, \& van Roon-Mom, 2019). Recent findings show that structural and/or functional abnormalities of the cerebellum are also associated with dystonia (Bologna \& Berardelli, 2018) and chorea (Walker, 2016). Several reports demonstrated a role of the cerebellum in DYT1 hereditary dystonia (Fremont, Tewari, Angueyra, \& Khodakhah, 2017; Vanni et al., 2015). Interestingly, dystonia, chorea/athetosis and ataxia are common movements abnormalities in GNAO1 patients (Arya, Spaeth, Gilbert, Leach, \& Holland, 2017; Kelly et al., 2019; Schorling et al., 2017). Structurally, a core circuit in the cerebellum mediates all its functions (Eccles, 1967; Reeber, Otis, \& Sillitoe, 2013). This circuit centers on PCs, the axons of which are the sole output of the cerebellar cortex (Brown et al., 2019). Each PC receives two major glutamatergic excitatory inputs: climbing fibers (CFs) and parallel fibers (PFs), and two sets of GABAergic inhibitory inputs from molecular layer internuerons (stellate and basket cells). We thus investigated whether GNAO mutant mice demonstrated alteres synaptic input to PCs. 
We report here decreased inhibitory input from cerebellar presynaptic GABAergic terminals upon PCs; there was a reduced frequency of sIPSCs and especially mIPSCs in the mutant mouse cerebellar slices but no change in EPSCs. A likely mechanism underlying this reduction in spontaneous release of GABA is that a LOF $G_{0}$ mutant frees up more $G \beta \gamma$ to mediate presynaptic inhibition. Interestingly, the $\mathrm{GABA}_{B}$ receptor, which selectively controls mIPSCs, does not appear to be involved in the action of the mutant protein. There were no significant changes in inhibitory synapse morphology upon PCs and a modest decrease in molecular layer interneuron count which is unlikely to solely account for the reduction of IPSCs. These observations, and the reduced $G \alpha_{0}$ expression in brain, with the normal levels of $\mathrm{G} \beta \gamma$, strongly support a model with a haploinsufficient LOF Gnao1 mutant which mainly functions through the receptor-independent release of free GßY subunits in neurons to suppress the activity of inhibitory neurons in the cerebellum of the Gnao1 mutant mice. 


\section{Materials and Methods}

All animal procedures complied with the U.S. National Institutes of Health guidelines on animal care and were approved by the MSU Institutional Committee on Animal Care and Use. The G203R mutation was introduced into the Gnao1 gene of the C57BL/6J mice by CRISPRCas9 and was previously considered to be a gain-of-function (GOF) mutation (Feng et al., 2019). Here, we identity an unexpected mutation that changes two bases 13 and 14 bp upstream of the designed G203R mutation (Figure 1). This converts the AGG at the splice acceptor site on exon 6 to an AAA which does not splice correctly. RT-PCR analysis and sequencing showed that there was virtually not correctly spliced mutant Gnao1 RNA that contained the G203R mutant allele. Western blots showed that the mutant mice had reduced expression of $G \alpha_{\circ}$ protein thus resulting in a haploinsufficient LOF mechanism. Thus, in this report, we refer these mice as the Gnao1 mutant mice. Gnao1 mutant male mice, generated from founders were crossed with female WT C57BL/6J mice from Jackson Labs (Bar Harbor, ME). Animals used for this study were between

5 and 10 weeks old. Only male heterozygous mutant animals were used due to the stronger behavioral phenotypes (Feng et al., 2019).

\section{Tissue preparation and solutions}

Mice were sacrificed by direct cervical dislocation and cerebellums were rapidly dissected. Parasagittal cerebellar slices $(250 \mu \mathrm{m})$ were prepared using a Vibrotome ${ }^{\mathrm{TM}} 1000$ (Leica, Wetzlar, Germany) according to previously described methods by Yuan and Atchison (Yuan \& Atchison, 1999, 2003b, 2007, 2016). Before slicing, cerebellums were transferred into a chilled oxygenated 
sucrose-based slicing solution containing (in mM): $62.5, \mathrm{NaCl} ; 107$, sucrose; $2.5, \mathrm{KCl} ; 5, \mathrm{MgCl}_{2}$;

1.25, $\mathrm{KH}_{2} \mathrm{PO}_{4} ; 26, \mathrm{NaHCO}_{3} ; 0.5, \mathrm{CaCl}_{2}$ and 20, D-glucose (pH 7.35-7.4 when saturated with $95 \% \mathrm{O}_{2} / 5 \% \mathrm{CO}_{2}$ at room temperature of $\left.22-25^{\circ} \mathrm{C}\right)$. Slices were incubated in the oxygenated slicing solution for $15 \mathrm{~min}$, then transferred into standard artificial cerebrospinal fluid (ACSF) solution at room temperature for at least $60 \mathrm{~min}$ before electrophysiological recordings. The standard ACSF contains (in mM): 125, $\mathrm{NaCl} ; 2.5, \mathrm{KCl} ; 1, \mathrm{MgCl}_{2} ; 1.25, \mathrm{KH}_{2} \mathrm{PO}_{4} ; 26, \mathrm{NaHCO}_{3} ; 2$, $\mathrm{CaCl}_{2}$ and 20, D-glucose ( $\mathrm{pH} 7.35-7.4$ saturated with $95 \% \mathrm{O}_{2} / 5 \% \mathrm{CO}_{2}$ at room temperature).

\section{Electrophysiological recording}

Whole-cell patch clamp recording methods were detailed in previous publications (Yuan \& Atchison, 1999, 2003b, 2007, 2016). Slices were placed in a recording chamber and perfused with standard ACSF bubbled with $95 \% \mathrm{O}_{2} / 5 \% \mathrm{CO}_{2}$. Individual neurons were visualized with a Nomarski 40X water immersion lens with infrared differential interference contrast optics using a Nikon E600FN upright microscope (Nikon Inc., Chicago, IL). Recording electrodes were fire polished and had a resistance of 3-7 $\mathrm{M} \Omega$ when filled with pipette solutions. For recording sIPSCs and mIPSCs, the pipette solution consisted of (in mM) 140, CsCl; 0.4, GTP; 2, Mg-ATP; 0.5, $\mathrm{CaCl}_{2} ; 5$, Phosphocreatine $\mathrm{Na}_{2} ; 5$, EGTA-CsOH; 10, HEPES (pH 7.3 adjusted with CsOH). For recording sEPSCs and mEPSCs, the pipette solution consisted of (in mM) 140, K-Gluconate; 4 $\mathrm{NaCl}$; 0.4, GTP; 2, Mg-ATP; 0.5, $\mathrm{CaCl}_{2} ;$ 5, EGTA-CsOH; 10, HEPES (pH 7.3 adjusted with $\mathrm{KOH}$ ). The holding potential was $-70 \mathrm{mV}$ for recording of both IPSCs and EPSCs. For recording inhibitory currents, 6-Cyano-7-nitroquinoxaline-2,3-dione (CNQX, $10 \mu \mathrm{M})$ and amino-5- 
phosphonopentanoic acid (APV, $100 \mu \mathrm{M})$ were added to the external solution to block glutamate receptor-mediated sEPSCs. For recordings of miniature IPSCs (mIPSCs), $0.5 \mu \mathrm{M}$ tetrodotoxin (TTX) was added to the external solution in addition to CNQX and APV. For recording sEPSCs, bicuculline $(10 \mu \mathrm{M})$ was added to the external solution to block GABA receptor-mediated sIPSCs. For recording of mEPSCs, the external solution was supplemented with $0.5 \mu \mathrm{M}$ TTX in addition to bicuculline. Whole cell currents were filtered at 2-5 kHz with an 8-pole low-pass Bessel filter and digitized at $10-20 \mathrm{kHz}$ for later off-line analysis using the pClamp 9.0 program (Molecular Devices, Inc., Sunnyvale, CA). All experiments were carried out at room temperature $\left(22-25^{\circ} \mathrm{C}\right)$.

\section{Pharmacology}

The following agents were used: CNQX disodium salts (Sigma-Aldrich, St. Louis, MO), APV acid solid (Sigma-Aldrich, St. Louis, MO), TTX (Tocris, Bristol, UK), pertussis toxin (PTX) (List Biological Laboratories, Campbell, CA), baclofen (Sigma-Aldrich, St. Louis, MO), NEM (SigmaAldrich, St. Louis, MO), UK14,304 (Sigma-Aldrich, St. Louis, MO), CGP36216 hydrochloride (Cayman Chemical, Ann Arbor, MI), cadmium chloride (Sigma-Aldrich, St. Louis, MO). All drugs were made up as 1000 x concentrated stock solutions in distilled water, aliquoted and stored at $\sim 20^{\circ} \mathrm{C}$. Aliquots were thawed and dissolved in oxygenated ACSF immediately prior to use.

\section{SDS PAGE and Western Blots}

Male mice (6-8 weeks old) were sacrificed, and their brains were dissected into different regions and flash-frozen in liquid nitrogen. For Western Blot analysis, tissues were thawed on ice and homogenized for $5 \mathrm{~min}$ with $0.5 \mathrm{~mm}$ zirconium beads in a Bullet Blender (Next Advance; 
Troy, NY) in RIPA buffer (20mM Tris-HCl, pH7.4, 150mM NaCl, 1mM EDTA, 1mM $\beta-$ glycerophospate, $1 \%$ Triton $\mathrm{X}-100$ and $0.1 \%$ SDS) with a protease inhibitor cocktail (Roche/1 tablet in $10 \mathrm{~mL}$ RIPA). Homogenates were centrifuged for $5 \mathrm{~min}$ at $4^{\circ} \mathrm{C}$ at $13,000 \times \mathrm{G}$. Supernatants were collected and protein concentrations determined using the bicinchoninic acid method (BCA method; Pierce; Rockford, IL). Protein concentration was normalized for all tissues with RIPA buffer and 2x SDS sample buffer containing $\beta$-mercaptoethanol (Sigma-Aldrich, St. Louis, MO) was added. Thirty $\mu \mathrm{g}$ of protein was loaded onto a $12 \%$ Bis-Tris gel (homemade), and samples were separated for $1.5 \mathrm{hrs}$ at $160 \mathrm{~V}$. Proteins were then transferred to an ImmobilonFL PVDF membrane (Millipore, Billerica, MA) on ice either for $2 \mathrm{~h}$ at $100 \mathrm{~V}, 400 \mathrm{~mA}$ or overnight at $30 \mathrm{~V}, 50 \mathrm{~mA}$. Immediately after transfer, PDVF membranes were washed and blocked in Odyssey PBS blocking buffer (LI-COR Biosciences, Lincoln, NE) for $40 \mathrm{~min}$ at RT. The membranes were then incubated with anti-Ga (rabbit; 1:1,000; sc-387; Santa Cruz biotechnologies, Santa Cruz, CA) or anti-G $\beta$ (recommended for detection of $G \beta_{1}, G \beta_{2}, G \beta_{3}$ and Gß4; mouse; 1:1000; sc-378; Santa Cruz biotechnologies, Santa Cruz, CA) and anti-actin (goat; 1:1,000; sc-1615; Santa Cruz) antibodies diluted in Odyssey blocking buffer with $0.1 \%$ Tween20 overnight at $4^{\circ} \mathrm{C}$. Following four 5 -min washes in phosphate-buffered saline with $0.1 \%$ Tween20 (PBS-T), the membrane was incubated for $1 \mathrm{hr}$ at room temperature with secondary antibodies (1:10,000; IRDye ${ }^{\circledR} 800 C W$ Donkey anti-rabbit; IRDye ${ }^{\circledR} 800 C W$ Donkey anti-mouse; IRDye® 680RD Donkey anti-goat; LI-COR Biosciences) diluted in Odyssey blocking buffer with $0.1 \%$ Tween-20. The membrane was subjected to four 5-min washes in PBS-T and a final rinse 
in PBS for 5 minutes. The membrane was kept in the dark and the infrared signals at 680 and

800nm were detected with an Odyssey Fc image system (LI-COR Biosciences). The Ga。 polyclonal antibody recognizes an epitope located between positions 90-140 of the Ga。 protein (Santa Cruz, personal communication).

\section{Tissue preparation and solutions}

For immunofluorescence experiments, cerebella were drop-fixed in $4 \%$ paraformaldehyde for 3 days at $4^{\circ} \mathrm{C}$. Tissues were then cryoprotected in $30 \%$ sucrose for 2 days at $4^{\circ} \mathrm{C}$ before being frozen in Tissue-Tek O.C.T. Compound (Sakura Finetek USA, Inc., Torrance, CA). Parasagittal cerebellar sections were generated on a Cryostat (Fisher Scientific, Hampton, NH) at $30 \mu \mathrm{m}$. Tissue was stored free-floating in PBS and $0.1 \%$ sodium azide at $4^{\circ} \mathrm{C}$.

\section{Immunofluorescence}

For Kit-eGFP tissue, a dissection scope was used to identify medial slices of the cerebellar vermis corresponding to sections 20 \& 21 of the sagittal Allen Mouse Brain Atlas. These sections were then mounted with ProLong Gold Antifade Mountant (Invitrogen, Waltham, MA) for imaging.

For immunohistochemistry, slices were allowed to warm to room temperature, rinsed in PBS, then permeabilized with PBS and $0.3 \%$ Triton $\mathrm{X}-100$ for 30 minutes. Tissue was then blocked for 30 minutes in PBS plus 20\% newborn calf serum (NBCS) and $0.3 \%$ Triton X-100. Slices were incubated in primary antibodies overnight at $4^{\circ} \mathrm{C}$, rinsed with $\mathrm{PBS}$, and incubated in secondary antibodies for 60 minutes at room temperature on a shaker. After being rinsed in PBS, slices were mounted as described. The following primary antibodies were used, diluted in PBS plus $2 \%$ 
NBCS and $0.3 \%$ Triton X-100: mouse anti-Glutamate decarboxylase (65 kD isoform, GAD65;

1:1500; ab26113; Abcam, Cambridge, United Kingdom), rabbit anti-Calbindin (1:3000; sysy-214

002; Synaptic Systems, Göttingen, Germany). Secondary antibodies were diluted similarly and include Alexa Fluor conjugated -488 and -546 (1:500; Invitrogen, Waltham, MA).

\section{Kit-eGFP labeling of molecular layer inhibitory neurons}

In postnatal mice, Kit is expressed at the transcript and protein level in GABAergic molecular layer interneurons (MLIs) of the cerebellar cortex. To visualize MLIs, we utilized a previously established BAC transgenic mouse line harboring an eGFP-polyA sequence regulated by the Kit locus (Heintz, 2004). In both male and female mice, and across all generations of backcrossing to a C57BL/6J background, we found that the pattern of GFP expression matched the literature for Kit expression in the cerebellar cortex: expression in the MLIs, and sparse expression in Golgi cells (Amat et al., 2017; Hirota et al., 1992; Keshet et al., 1991; Manova et al., 1992; Motro, van der Kooy, Rossant, Reith, \& Bernstein, 1991). The Kit eGFP strain used in this study was generated from (Tg(Kit-EGFP)IF44Gsat/Mmucd; Gensat) (Heintz, 2004) that had been backcrossed for greater than 5 generations to C57BL6/J (Stock No: 000664, The Jackson Laboratory). These mice were further crossed with heterozygous Gnao1 mutant mice to generate Kit-eGFP expressing littermates with WT or LOF Gnao1 alleles.

\section{Image Analysis}

Epifluorescent images were collected with a Nikon Eclipse Ti2-E Inverted Microscope (Nikon Inc., Chicago, IL) at 20X magnification. Images shown are $Z$ stacks of the entire focus plane at 
a step size of $0.9 \mu \mathrm{m}$. True confocal images were captured on an Olympus FV1000 confocal laser scanning microscope (Olympus America Inc., Center Valley, PA) with a 63X oil-immersion objective and a step size of $0.43 \mu \mathrm{m}$. Z stacks of 14 slices were collected to capture the pinceau and perisoma of multiple PCs. All images were edited in the Fiji distribution of ImageJ2 (Schindelin et al., 2012). GAD65 and 40X Kit-eGFP images were deconvolved using the DeconvolutionLab plugin and the Richardson-Lucy algorithm, 10 iterations. Point-spread functions were generated using the PSF Generator plugin with the Born \& Wolf 3D Optical Model (Kirshner, Aguet, Sage, \& Unser, 2013).

\section{Statistical Analysis}

Electrophysiological data analysis was performed as described previously (Yuan \& Atchison, 1999, 2003b, 2007, 2016). The individual performing the analysis was blinded to the genotype until all results were recorded. In brief, spontaneous synaptic currents were first screened automatically using MiniAnalysis software (Synaptosoft Inc., Decatur, GA) with a set of prespecified parameters (i.e. period to search a local maximum; time before a peak for baseline; period to search a decay time; fraction of peak to find a decay time; period to average a baseline; area threshold; number of points to average for peak; direction of peak). They were accepted or rejected manually with an event detection amplitude threshold at $5 \mathrm{pA}$ for sIPSCs/mIPSCs and 3 pA for sEPSCs/mEPSCs as well as being assessed for the typical kinetic properties (fast rising phase and slow decay phase) of the spontaneous events. These thresholds were chosen based on the baseline noise level of each individual recording (baseline noise amplitude ranged from 
0.2 to $0.8 \mathrm{pA}$ ) so the thresholds were from $6-25 \mathrm{x}$ the noise level. Unless otherwise specified, synaptic events per cell collected over a 2-min period were averaged to calculate the frequency and amplitude of spontaneous synaptic currents. Amplitudes of currents were measured after subtraction of the baseline noise. MiniAnalysis-derived results were plotted in GraphPad Prism (GraphPad; LaJolla, CA). Results from more than one neuron from a single animal were averaged prior to statistical analysis. Some graphs, when indicated, show points for each individual neuron while bar graphs and error bars are calculated from the per animal data. Data are presented as mean value \pm SEM, where $n=$ number of animals. Statistical significance was determined using unpaired Student's t-test unless stated otherwise. A p value $<0.05$ was deemed significant.

Quantification of infrared (IR) Western blot signals was performed using Image Studio Lite (LI-COR Biosciences). Individual bands were normalized to the corresponding actin signals, and WT $\mathrm{Ga}_{\circ}$ was set as control for each blot. All data were analyzed using GraphPad Prism 8.0 (GraphPad; LaJolla, CA).

For cell counts, images were thresholded to mask cells within the focus plane. The watershed plugin in ImageJ2 was used to separate overlapping cells. The Analyze Particles function was used to count cells and measure their sizes. To avoid artifact, the average intensity of particles measured during cell counts were compared between WT and Gnao1 group, no significant difference was observed. Pinceau were traced manually from Z-projections. 
Perisomatic contacts with basket cell axons were assessed by measuring the thickness of KiteGFP fluorescence at each PC's widest point.

GAD65 staining in the molecular layer was also quantified using the Analyze Particles function. Measurements were taken in a rectangular ROI above the PC layer on a projection of 3 Z-steps. To exclude off-target vasculature staining, particles larger than $3 \mu m^{2}$ were not measured. Pinceau were measured on a projection of 3 Z-steps at each PC's widest point. The magic wand tool was used to define each ROI. GAD65 puncta on the periphery of each PC were manually counted to assess perisomatic synapses. For validation, the cell counts were repeated at a different magnification using a different method (auto-thresholding vs. manual). 


\section{Results}

\section{Identification of second site mutation}

C57BL/6J mice containing a G203R mutant allele were generated as described (Feng et al, 2019) where the mutant allele introduces a new Sac II restriction site which was used for genotyping. Subsequently, a tail snip from a heterozygous G203R mutant mouse was obtained for genomic PCR and Sanger sequencing to define the local DNA sequence around the mutation. In addition to the G203R mutation, there were two additional heterozygous base alterations just upstream of the designed mutation (Figure 1). This resulted in the sequence AAA replacing the AGG at the exon 6 splice acceptor site. The second mutation (AGG>GAA) destroys an Sbf1 restriction site that is present in the wild-type sequence. To determine whether this second mutation was a random mutation present in a single mutant mouse, we used genomic PCR and restriction digestion with Sacll (G203R) and Sbfl (splice site) and screened 52 mice from 10 litters. All 30 mice carrying the G203R mutation also had loss of the Sbf1 site and none of the 22 mice with the WT codon 203 sequence had the loss of Sbf1 digestion.

Review of older data from the founder mouse revealed that the second mutation was present at the initial development of the mouse line. The way the sequence data were collected (sequencing from a cloned PCR product) caused us to miss the fact that the sequence did not fully match the WT sequence. Thus all G203R mutant mice in this present study and in our previous publication (Feng et al., 2019) appear to have the second site mutation at the splice site. 


\section{Loss of splice site activity}

Introns nearly universally terminate in an AG base pair at the splice acceptor site. Since the second mutation converted an AGG to AAA it is highly likely to disrupt normal splicing of Exon 5 onto Exon 6. To determine if this was the case, we undertook RT-PCR with primers in exons 5 and 6 and in exons 5 and 7 to understand how splicing is perturbed by the second site mutation. RT-PCR of brain tissue from heterozygous G203R mutant mice using primers in exons 5 and 6 yielded a $218 \mathrm{bp}$ band of the expected size for normal splicing. Sequence analysis, however, showed only the WT sequence at codon 203. Therefore, there was no normal splicing in the G203R mutants. Those samples did reveal a faint band of higher molecular weight, which we isolated and sequenced, that showed a rare splicing event 45 bp upstream of the usual splice junction that occurred only in the G203R mutants (Figure 1). The sequence of this alternatively spliced cDNA showed a stop codon before codon 203.

RT-PCR using primers in exons 5 and 7 also revealed bands of the appropriate size 397 b.p. There was no evidence of skipping of exon 6 to produce a direct splice from exon 5 to exon 7 (expected size 267 b.p.). The low frequency insertion of 45 bp seen with the exon 5 and 6 primers was also evident in the samples from mutant mice for the exon 5-7 RT-PCR (Figure 1E).

\section{Gnao1 mutant mice exhibit decreased $G_{\circ}$ protein but no change in $G \beta$ levels}

We tested $\mathrm{Ga}_{\mathrm{o}}$ protein expression in whole brain and selected brain regions of WT and Gnao1 mice. Results showed a significant reduction in $\mathrm{G} \alpha_{\circ}$ protein expression ( $50 \%$ of WT) in whole brain (Figure 2A, 2C; $\mathrm{p}<0.0001)$. The decrease in $\mathrm{G} \alpha_{\mathrm{o}}$ protein expression was also 
significant in cerebellum, cortex, hippocampus, and striatum of the mutant mice (Figure 2B, 2D; $\mathrm{p}<0.05)$. No significant change was observed in the brainstem or the olfactory bulb.

Interestingly, expression levels of $\mathrm{G} \beta$ did not change in Gnao1 mutant mice (Figure 2E \& $2 \mathrm{~F}$ ). Given that $\mathrm{Ga}_{\circ}$ is the most abundant $\mathrm{Ga}$ subunit in brain, a decreased $\mathrm{Ga}_{\mathrm{o}}$ protein expression level accompanied by normal $G \beta$ protein levels suggests that there would be increased free Gßy subunits, which could lead to enhanced receptor-independent Gßy signaling.

\section{Presynaptic GABA release is suppressed in cerebellar PCs of Gnao1 mutant mice}

sIPSCs, which are considered to be due to AP-dependent GABA release, were isolated by adding $10 \mu \mathrm{M}$ CNQX and $100 \mu \mathrm{M}$ APV in standard ACSF to block glutamate signaling. sIPSC frequency was decreased by $40 \%$ in Gnao1 mice compared to their WT siblings (WT: $21.0 \pm 1.7$ $\mathrm{Hz}$; Gnao1: $12.7 \pm 2.5 \mathrm{~Hz}$; Figure $3 \mathrm{~A} \& 3 \mathrm{C}, \mathrm{p}<0.01$ ), but there was no difference in sIPSC amplitude (WT: $41.8 \pm 8.5$ pA; Gnao1: $36.7 \pm 7.4$ pA; Figure 3B \& 3D, n.s.), suggesting a presynaptic mechanism.

mIPSCs, which are due to AP-independent GABA release, were isolated by the further addition of $0.5 \mu \mathrm{M}$ TTX. As reported previously in cerebellar PCs, TTX significantly reduced mean sIPSC frequency and amplitude (Bardo, Robertson, \& Stephens, 2002; Boxall, 2000; Harvey \& Stephens, 2004; Yuan \& Atchison, 2003a). Slices from Gnao1 mice exhibited a marked $75 \%$ reduction in mIPSC frequency compared to those of WT mice (Figure $3 E \& 3 G, p<0.01$ ), but not in mIPSC amplitude (Figure 3F \& 3H, n.s.). The percentage change in mIPSC frequency was greater for mIPSCs than that for sIPSCs ( $75 \%$ vs $40 \%$ decrease). 


\section{Presynaptic glutamate release is not affected by the LOF Ga。 protein}

To investigate whether the LOF mutant affects the excitatory inputs to PCs, we recorded sEPSCs and mEPSCs from PCs. The AP-dependent sEPSCs were isolated with $10 \mu \mathrm{M}$ bicuculline in the bath and AP-independent mEPSCs were recorded with the further addition of $0.5 \mu \mathrm{M}$ TTX. Although the mutant $\mathrm{Ga}_{\circ}$ protein significantly decreased sIPSC and mIPSC frequency, EPSCs are seemingly affected in neither frequency nor amplitude for both sEPSCs and mEPSCs (Figure 4; sEPSC frequency: WT: $1.50 \pm 0.20 \mathrm{~Hz}$ vs. Gnao1: $1.36 \pm 0.43 \mathrm{~Hz}$, n.s.; sEPSC amplitude: WT: $7.52 \pm 0.92$ pA vs. Gnao1: $6.42 \pm 0.50$ pA, n.s.; mEPSC frequency: WT: $1.05 \pm 0.16 \mathrm{~Hz}$ vs. Gnao1: $0.99 \pm 0.46 \mathrm{~Hz}$, n.s.; mEPSC amplitude: WT: $6.39 \pm 0.91$ pA; Gnao1: $6.24 \pm 0.60$ pA, n.s. $)$

\section{Pertussis-toxin reverses the enhanced inhibition of mIPSC frequency in Gnao1 mice}

Considering the previously proposed GOF mechanism of the G203R mutant $\mathrm{Ga}_{\mathrm{o}}$, we examined the effects of PTX incubation on the AP-dependent and AP-independent IPSCs in cerebellar PCs. PTX catalyzes the ADP-ribosylation of $\alpha$ subunits of the heterotrimeric $\mathrm{G}_{\mathrm{i} / \mathrm{o}}$ family, thereby preventing the G proteins from interacting with GPCRs (Mangmool \& Kurose, 2011). Slices in this experiment were subject to incubation in ACSF containing $1 \mu \mathrm{g} / \mathrm{mL}$ PTX for more than 6 hours before recording. Surprisingly, PTX significantly increased the mIPSC frequency in slices from Gnao1 mice but had no effect on WT mice (WT: from $4.10 \pm 0.70 \mathrm{~Hz}$ to $3.40 \pm 0.68$ Hz, n.s.; Gnao1: from $1.31 \pm 0.16 \mathrm{~Hz}$ to $2.29 \pm 0.30 \mathrm{~Hz}, \mathrm{p}<0.01$; Figure 5B \& 5D). The mean amplitude of mIPSCs was not changed in either WT or Gnao1 mice after PTX incubation (WT: 
$12.1 \pm 1.6$ pA to $9.7 \pm 1.4$ pA, n.s., Gnao1: $19.6 \pm 1.6$ pA to $15.8 \pm 2.9$ pA, n.s.; Figure $5 C \& 5 E)$. In contrast to mIPSCs, sIPSC frequency was not affected by PTX in either WT or Gnao1 mice (Frequency: WT: $13.8 \pm 1.7 \mathrm{~Hz}$ to $10.9 \pm 3.6 \mathrm{~Hz}$, n.s.; Gnao1: $9.1 \pm 1.4 \mathrm{~Hz}$ to $12.5 \pm 2.3 \mathrm{~Hz}$, n.s.; Amplitude: WT: $18.9 \pm 3.4$ pA to $19.2 \pm 8.9$ pA, n.s.; Gnao1: $29.2 \pm 4.1$ pA to $24.4 \pm 4.5$ pA, n.s.;

Figure 5-1). Given the reduced expression of $\mathrm{G} \alpha_{\mathrm{o}}$ in the Gnao1 mutant mice, the effect of PTX to reverse the inhibition of mIPSCs is likely indirect (see Discussion).

\section{Effects of $G A B A_{B}$ receptors on $A P$-independent GABA release onto PCs}

To explore the effects of $\mathrm{GABA}_{B}$ receptors on reduced GABA release and to determine whether $\mathrm{GABA}_{\mathrm{B}}$ responses are altered in the Gnao1 mutant mice, mIPSCs were recorded in the presence of baclofen, a selective $\mathrm{GABA}_{\mathrm{B}}$ receptor agonist. After recording baseline mIPSCs, baclofen $(10 \mu \mathrm{M})$ was applied to the bath. Baclofen caused a clear reduction in mean mIPSC frequency in slices from both WT (from $5.47 \pm 0.80 \mathrm{~Hz}$ to $1.19 \pm 0.25 \mathrm{~Hz}, 78 \%$ inhibition, $p<0.001$ ) and Gnao1 mice (from $1.24 \pm 0.20 \mathrm{~Hz}$ to $0.65 \pm 0.11 \mathrm{~Hz}, 48 \%$ inhibition, $\mathrm{p}<0.05$ ) after 4 to $8 \mathrm{~min}$ (Figure 6C \& 6E). Mean mIPSC amplitude was unchanged by baclofen (Figure 6D \& 6F; WT: $12.8 \pm 2.3$ pA to $13.6 \pm 4.3$ pA, n.s.; Gnao1: $17.8 \pm 1.9$ pA to $17.3 \pm 1.6$ pA, n.s. $)$, consistent with a presynaptic mechanism of action. Interestingly, the application of baclofen did not affect sIPSCs, while $\alpha_{2}$ adrenergic receptors only regulate sIPSCs but not mIPSCs (Harvey \& Stephens, 2004; data not shown).

$\mathrm{G}_{0}$ or related $\mathrm{G}_{i}$ proteins contribute to the baclofen-induced inhibition of mIPSC frequency as previously reported (Harvey \& Stephens, 2004). PTX (1 $\mu \mathrm{g} / \mathrm{mL})$ eliminated baclofen-induced 
inhibition of mIPSC frequency (Figure 6-1 C, E). PTX did not affect mIPSC amplitude (Figure 6-

$2 \mathrm{D}, \mathrm{F})$. Cadmium $\mathrm{Cd}^{2+}$, which blocks calcium channels, did not affect the frequency or amplitudes of mIPSCs in either WT or Gnao1 mice (Figure 6-2) in contrast to the effect of PTX

(Figure 5). The baclofen-induced decrease of mIPSC frequency was also unaffected by $\mathrm{Cd}^{2+}$ (Figure 6-2) which implies direct synaptic inhibition rather than voltage-gated calcium channel effects as the mechanism.

No significant difference in the baclofen concentration-response curve between WT and Gnao1 mutant.

We tested the baclofen concentration dependence in reducing PC mIPSCs. Baclofen (1, 3, and $10 \mu \mathrm{M}$ ) was added cumulatively into the ACSF while recording mIPSCs. Higher concentrations of baclofen inhibited the mIPSC frequency to a greater extent. However, there was no significant difference in the baclofen concentration-response between WT and Gnao1 when the results were normalized to the baseline mIPSC level without baclofen (Figure 7). This observation suggests that the difference in mIPSC frequency caused by the Gnao1 mutant is independent of the activation of $G A B A_{B} R$, which would be expected for a signal caused by free $\mathrm{G} \beta \gamma$ due to reduced $\mathrm{G} \alpha_{\mathrm{o}}$ levels.

Pre-treatment with $G A B A_{B} R$ antagonist CGP36216 (100 $\left.\mu M\right)$ prevented baclofen-induced inhibition of mIPSC frequency but did not reverse Gnao1 mutant suppression of mIPSC frequency 
Pre-treating PCs with the $\mathrm{GABA}_{B} \mathrm{R}$ antagonist CGP36216 (100 $\left.\mu \mathrm{M}\right)$ did not enhance baseline mIPSC frequencies in either WT or Gnao1 cerebellar slices (Figure 8C). It did, however, eliminate the baclofen-induced inhibition of mIPSC frequency (Figure 8C). mIPSC amplitude was not affected (Figure 8D). The lack of effect of a GABA $R$ antagonist on baseline mIPSCs was observed previously with another $\mathrm{GABA}_{B} R$ antagonist (Harvey \& Stephens, 2004) and suggests that there is no tonic regulation of GABA release by $\mathrm{GABA}_{B}$ receptors in WT mice. Surprisingly, the same is true for the Gnao1 mutant mice, which have a suppressed mIPSC frequency, further supporting the independence of the effect of Gnao1 mutant from GABA $A_{B}$ receptors. These data are consistent with a presynaptic role of $\mathrm{G}_{\mathrm{o} / \mathrm{i}}$ subunits in baclofen-induced inhibition of AP-independent GABA release onto PCs by a mechanism that is also independent of membrane calcium channels. The direct $\mathrm{G} \beta \gamma$-mediated regulation of synaptic vesicle fusion (Blackmer et al., 2001; Zurawski et al., 2017) seems to be the most likely explanation.

The number of cerebellar molecular layer interneurons is modestly reduced in Gnao1

\section{mutant mice}

Analysis of a c-kit eGFP reporter mouse revealed that interneuron number was significantly lower in cerebellar molecular layer (Figure 9). Cerebellar molecular layer mainly contains basket and stellate interneurons, which are important controllers of cerebellar cortical output by controlling the inhibitory synaptic input to PCs (Brown et al., 2019). Although there were fewer interneurons in Gnao1 mutant's cerebellar molecular layer, synapse count or axons contacts around PCs from basket and stellate cells remained unchanged (Figure 9-1 and 9-2). 


\section{Discussion}

Mutations in $\mathrm{G} \alpha_{0}$ result in GNAO1 encephalopathies which include severe epilepsy (Nakamura et al., 2013) or movement disorders (Ananth et al., 2016; Feng, Khalil, Neubig, \& Sidiropoulos, 2018; Saitsu et al., 2016) with profound impacts on affected children. While cellbased studies (Feng et al., 2018; Feng et al., 2017) and animal behavioral models (Feng et al., 2019; Larrivee et al., 2019) have provided some mechanistic information about the human GNAO1 mutations, there have been no neurophysiological studies of effects on synaptic transmission. Here, we show that a LOF mutant mouse with haploinsufficient $\mathrm{G} \alpha_{\mathrm{o}}$ protein has impaired inhibitory signaling in cerebellar PCs, which is most likely due to increased levels of free $G \beta \gamma$ in inhibitory neurons.

Movement disorders may originate from abnormalities in several brain regions including striatum, cortex, and cerebellum. Cerebellar PCs have abundant $\mathrm{G}_{\mathrm{o}}$ expression (Asano, Semba, Kamiya, Ogasawara, \& Kato, 1988) so cerebellar PCs were the main focus of this study. Mutant mice exhibited decreased inhibitory signaling to PCs. The frequencies of sIPSCs and especially mIPSCs were reduced without changes in amplitude suggesting a pre-synaptic mechanism.

$\mathrm{GABA}_{B}$ receptor-activated $\mathrm{Ga}_{\mathrm{o}}$ is the primary mediator of inhibition of the non-AP relatedmIPSCs (Harvey \& Stephens, 2004), however, the GABAB receptor does not appear to be necessary for the actions of the mutant-dependent presynaptic inhibition. The mutant did not cause a leftward shift in the concentration-response curve for baclofen on the mIPSC frequency. More tellingly, the GABA $A_{B}$ antagonist CGP36214 did not alter the baseline mIPSC frequency 
in either WT or Gnao1 mice at concentrations that prevented baclofen-induced inhibition of mIPSC frequency.

Moreover, the level of mutant $\mathrm{G} \alpha_{\mathrm{o}}$ is about half that of WT in multiple brain regions including cerebellum. All these results are consistent with a haploinsufficient LOF Gnao1 mutant function. With low levels of $\mathrm{G} \alpha_{0}$ (the most abundant $\mathrm{G} \alpha$ subunit (Jiang \& Bajpayee, 2009)) and normal amounts of $G \beta \gamma$, one would expect increased free $G \beta \gamma$ due to altered subunit stoichiometry. The enhanced free $G \beta \gamma$ could directly inhibit synaptic vesicle release through actions on SNARE complex or $\mathrm{Ca}^{2+}$ influx (Feng et al., 2018; Zurawski et al., 2017; Zurawski, Rodriguez, Hyde, Alford, \& Hamm, 2016). The lack of effect of calcium channel block by $\mathrm{Cd}^{2+}$ on the mIPSC regulation would be consistent with this mechanism. One potentially incongruous finding in this study is that G $\alpha_{o}$ blockers, PTX, significantly increased the mIPSC frequency in Gnao1 mutant mice, while one would expect the opposite for a LOF Gnao1 mutant. Although PTX is selective for $\mathrm{G} \alpha_{\mathrm{o} / \mathrm{i}}$, it can also lead to changes that may ultimately increase GABA release. For example, PTX locks $G \alpha_{0}$ into an inactive state which makes it unable to release $G \beta \gamma$ to inhibit adenylyl cyclase (AC), causing a cAMP accumulation (Mangmool \& Kurose, 2011). Rises in cAMP activate PKA, which enhances release probability at many synapses (Leenders \& Sheng, 2005). Alternatively, PTX-mediated ADP-ribosylation of $\mathrm{G} \alpha_{\mathrm{o}} / \beta \gamma$ could stabilize the GDP-bound heterotrimer and reduce free G $\beta \gamma$ resulting from spontaneous GTP binding to G $\alpha_{\circ}$ or could recruit $\mathrm{G} \beta \gamma$ to $\mathrm{G} \alpha_{i}$ subunits (Figure 10). 
The limited role for receptors in the neurophysiological alterations in cerebellum reported here provide a cautionary tale for the suggestion that we have made for using GPCR antagonists to ameliorate movement disorders in patients (Feng et al. 2017; Feng et al. 2018). It is possible, however, that different signal outputs or brain regions may be affected differently, and distinct mutant alleles may also show different patterns. Future studies exploring mutant GNAO1 mechanisms in different brain regions and cell-types as well as exploring the multiple $\mathrm{G}_{0_{0^{-}}}$ mediated signal outputs with different mutant alleles will be needed to test the generality of the model proposed here. 


\section{References}

Amat, S. B., Rowan, M. J. M., Gaffield, M. A., Bonnan, A., Kikuchi, C., Taniguchi, H., \& Christie, J. M. (2017). Using c-kit to genetically target cerebellar molecular layer interneurons in adult mice. PLoS One, 12(6), e0179347. doi:10.1371/journal.pone.0179347

Ananth, A. L., Robichaux-Viehoever, A., Kim, Y. M., Hanson-Kahn, A., Cox, R., Enns, G. M., . . . Bernstein, J. A. (2016). Clinical Course of Six Children With GNAO1 Mutations Causing a Severe and Distinctive Movement Disorder. Pediatr Neurol, 59, 81-84. doi:10.1016/j.pediatrneurol.2016.02.018

Arya, R., Spaeth, C., Gilbert, D. L., Leach, J. L., \& Holland, K. D. (2017). GNAO1-associated epileptic encephalopathy and movement disorders: c.607G>A variant represents a probable mutation hotspot with a distinct phenotype. Epileptic Disord, 19(1), 67-75. doi:10.1684/epd.2017.0888

Asano, T., Semba, R., Kamiya, N., Ogasawara, N., \& Kato, K. (1988). Go, a GTP-binding protein: immunochemical and immunohistochemical localization in the rat. J Neurochem, 50(4), 1164-1169. doi:10.1111/j.1471-4159.1988.tb10588.x

Bardo, S., Robertson, B., \& Stephens, G. J. (2002). Presynaptic internal Ca2+ stores contribute to inhibitory neurotransmitter release onto mouse cerebellar Purkinje cells. $\mathrm{Br} J$ Pharmacol, 137(4), 529-537. doi:10.1038/sj.bjp.0704901

Blackmer, T., Larsen, E. C., Takahashi, M., Martin, T. F., Alford, S., \& Hamm, H. E. (2001). G protein betagamma subunit-mediated presynaptic inhibition: regulation of exocytotic fusion downstream of Ca2+ entry. Science, 292(5515), 293-297. doi:10.1126/science.1058803

Bologna, M., \& Berardelli, A. (2018). The cerebellum and dystonia. Handb Clin Neurol, 155, 259272. doi:10.1016/B978-0-444-64189-2.00017-2

Boxall, A. R. (2000). GABAergic mIPSCs in rat cerebellar Purkinje cells are modulated by TrkB and mGluR1-mediated stimulation of Src. J Physiol, 524 Pt 3, 677-684. doi:10.1111/j.1469-7793.2000.00677.x

Brown, A. M., Arancillo, M., Lin, T., Catt, D. R., Zhou, J., Lackey, E. P., . . Sillitoe, R. V. (2019). Molecular layer interneurons shape the spike activity of cerebellar Purkinje cells. Sci Rep, 9(1), 1742. doi:10.1038/s41598-018-38264-1 
Buijsen, R. A. M., Toonen, L. J. A., Gardiner, S. L., \& van Roon-Mom, W. M. C. (2019). Genetics, Mechanisms, and Therapeutic Progress in Polyglutamine Spinocerebellar Ataxias. Neurotherapeutics, 16(2), 263-286. doi:10.1007/s13311-018-00696-y

Eccles, J. C. (1967). Circuits in the cerebellar control of movement. Proc Natl Acad Sci U S A, 58(1), 336-343. doi:10.1073/pnas.58.1.336

Feng, H., Khalil, S., Neubig, R. R., \& Sidiropoulos, C. (2018). A mechanistic review on GNAO1associated movement disorder. Neurobiol Dis. doi:10.1016/j.nbd.2018.05.005

Feng, H., Larrivee, C. L., Demireva, E. Y., Xie, H., Leipprandt, J. R., \& Neubig, R. R. (2019). Mouse models of GNAO1-associated movement disorder: Allele- and sex-specific differences in phenotypes. PLoS One, 14(1), e0211066. doi:10.1371/journal.pone.0211066

Feng, H., Sjogren, B., Karaj, B., Shaw, V., Gezer, A., \& Neubig, R. R. (2017). Movement disorder in GNAO1 encephalopathy associated with gain-of-function mutations. Neurology, 89(8), 762-770. doi:10.1212/WNL.0000000000004262

Fremont, R., Tewari, A., Angueyra, C., \& Khodakhah, K. (2017). A role for cerebellum in the hereditary dystonia DYT1. Elife, 6. doi:10.7554/eLife.22775

Harvey, V. L., \& Stephens, G. J. (2004). Mechanism of GABA receptor-mediated inhibition of spontaneous GABA release onto cerebellar Purkinje cells. Eur J Neurosci, 20(3), 684700. doi:10.1111/j.1460-9568.2004.03505.x

Heintz, N. (2004). Gene expression nervous system atlas (GENSAT). Nat Neurosci, 7(5), 483. doi:10.1038/nn0504-483

Hirota, S., Ito, A., Morii, E., Wanaka, A., Tohyama, M., Kitamura, Y., \& Nomura, S. (1992). Localization of mRNA for c-kit receptor and its ligand in the brain of adult rats: an analysis using in situ hybridization histochemistry. Brain Res Mol Brain Res, 15(1-2), 47-54. doi:10.1016/0169-328x(92)90150-a

Ikeda, S. R. (1996). Voltage-dependent modulation of N-type calcium channels by G-protein beta gamma subunits. Nature, 380(6571), 255-258. doi:10.1038/380255a0

Jiang, M., \& Bajpayee, N. S. (2009). Molecular mechanisms of go signaling. Neurosignals, 17(1), 23-41. doi:10.1159/000186688

Kelly, M., Park, M., Mihalek, I., Rochtus, A., Gramm, M., Perez-Palma, E., . . Poduri, A. (2019). 
Spectrum of neurodevelopmental disease associated with the GNAO1 guanosine triphosphate-binding region. Epilepsia, 60(3), 406-418. doi:10.1111/epi.14653

Keshet, E., Lyman, S. D., Williams, D. E., Anderson, D. M., Jenkins, N. A., Copeland, N. G., \& Parada, L. F. (1991). Embryonic RNA expression patterns of the c-kit receptor and its cognate ligand suggest multiple functional roles in mouse development. EMBO J, 10(9), 2425-2435. Retrieved from https://www.ncbi.nlm.nih.gov/pubmed/1714375

Kirshner, H., Aguet, F., Sage, D., \& Unser, M. (2013). 3-D PSF fitting for fluorescence microscopy: implementation and localization application. J Microsc, 249(1), 13-25. doi:10.1111/j.13652818.2012.03675.x

Larrivee, C. L., Feng, H., Quinn, J. A., Shaw, V. S., Leipprandt, J. R., demireva, E. Y., . . Neubig, R. R. (2019). Preprint: Mice with GNAO1 R209H Movement Disorder Variant Display Hyperlocomotion Alleviated by Risperidone. BioRxiv. Retrieved from https://doi.org/10.1101/662031

Leenders, A. G., \& Sheng, Z. H. (2005). Modulation of neurotransmitter release by the second messenger-activated protein kinases: implications for presynaptic plasticity. Pharmacol Ther, 105(1), 69-84. doi:10.1016/j.pharmthera.2004.10.012

Mangmool, S., \& Kurose, H. (2011). G(i/o) protein-dependent and -independent actions of Pertussis Toxin (PTX). Toxins (Basel), 3(7), 884-899. doi:10.3390/toxins3070884

Manova, K., Bachvarova, R. F., Huang, E. J., Sanchez, S., Pronovost, S. M., Velazquez, E., ... Besmer, P. (1992). c-kit receptor and ligand expression in postnatal development of the mouse cerebellum suggests a function for c-kit in inhibitory interneurons. $J$ Neurosci, 12(12), 4663-4676. Retrieved from https://www.ncbi.nlm.nih.gov/pubmed/1281492

Motro, B., van der Kooy, D., Rossant, J., Reith, A., \& Bernstein, A. (1991). Contiguous patterns of c-kit and steel expression: analysis of mutations at the W and SI loci. Development, 113(4), 1207-1221. Retrieved from https://www.ncbi.nlm.nih.gov/pubmed/1811937

Nakamura, K., Kodera, H., Akita, T., Shiina, M., Kato, M., Hoshino, H., . . Saitsu, H. (2013). De Novo mutations in GNAO1, encoding a Galphao subunit of heterotrimeric G proteins, cause epileptic encephalopathy. Am J Hum Genet, 93(3), 496-505. doi:10.1016/j.ajhg.2013.07.014

Reeber, S. L., Otis, T. S., \& Sillitoe, R. V. (2013). New roles for the cerebellum in health and 
disease. Front Syst Neurosci, 7, 83. doi:10.3389/fnsys.2013.00083

Saitsu, H., Fukai, R., Ben-Zeev, B., Sakai, Y., Mimaki, M., Okamoto, N., . . Matsumoto, N. (2016). Phenotypic spectrum of GNAO1 variants: epileptic encephalopathy to involuntary movements with severe developmental delay. Eur J Hum Genet, 24(1), 129-134. doi:10.1038/ejhg.2015.92

Schindelin, J., Arganda-Carreras, I., Frise, E., Kaynig, V., Longair, M., Pietzsch, T., ... Cardona, A. (2012). Fiji: an open-source platform for biological-image analysis. Nat Methods, 9(7), 676-682. doi:10.1038/nmeth.2019

Schorling, D. C., Dietel, T., Evers, C., Hinderhofer, K., Korinthenberg, R., Ezzo, D., ... Kirschner, J. (2017). Expanding Phenotype of De Novo Mutations in GNAO1: Four New Cases and Review of Literature. Neuropediatrics, 48(5), 371-377. doi:10.1055/s-0037-1603977

Sunahara, R. K., \& Taussig, R. (2002). Isoforms of mammalian adenylyl cyclase: multiplicities of signaling. Mol Interv, 2(3), 168-184. doi:10.1124/mi.2.3.168

Vanni, V., Puglisi, F., Bonsi, P., Ponterio, G., Maltese, M., Pisani, A., \& Mandolesi, G. (2015). Cerebellar synaptogenesis is compromised in mouse models of DYT1 dystonia. Exp Neurol, 271, 457-467. doi:10.1016/j.expneurol.2015.07.005

Walker, R. H. (2016). The non-Huntington disease choreas: Five new things. Neurol Clin Pract, 6(2), 150-156. doi:10.1212/CPJ.0000000000000236

Yuan, Y., \& Atchison, W. D. (1999). Comparative effects of methylmercury on parallel-fiber and climbing-fiber responses of rat cerebellar slices. J Pharmacol Exp Ther, 288(3), 10151025. Retrieved from https://www.ncbi.nlm.nih.gov/pubmed/10027838

Yuan, Y., \& Atchison, W. D. (2003a). Electrophysiological studies of neurotoxicants on central synaptic transmission in acutely isolated brain slices. Curr Protoc Toxicol, Chapter 11, Unit11 11. doi:10.1002/0471140856.tx1111s17

Yuan, Y., \& Atchison, W. D. (2003b). Methylmercury differentially affects GABA(A) receptormediated spontaneous IPSCs in Purkinje and granule cells of rat cerebellar slices. $J$ Physiol, 550(Pt 1), 191-204. doi:10.1113/jphysiol.2003.040543

Yuan, Y., \& Atchison, W. D. (2007). Methylmercury-induced increase of intracellular Ca2+ increases spontaneous synaptic current frequency in rat cerebellar slices. Mol Pharmacol, 71(4), 1109-1121. doi:10.1124/mol.106.031286 
Yuan, Y., \& Atchison, W. D. (2016). Multiple Sources of Ca2+ Contribute to MethylmercuryInduced Increased Frequency of Spontaneous Inhibitory Synaptic Responses in Cerebellar Slices of Rat. Toxicol Sci, 150(1), 117-130. doi:10.1093/toxsci/kfv314

Zhang, Q., Dickson, A., \& Doupnik, C. A. (2004). Gbetagamma-activated inwardly rectifying K(+) (GIRK) channel activation kinetics via Galphai and Galphao-coupled receptors are determined by Galpha-specific interdomain interactions that affect GDP release rates. $J$ Biol Chem, 279(28), 29787-29796. doi:10.1074/jbc.M403359200

Zurawski, Z., Page, B., Chicka, M. C., Brindley, R. L., Wells, C. A., Preininger, A. M., ... Hamm, H. E. (2017). Gbetagamma directly modulates vesicle fusion by competing with synaptotagmin for binding to neuronal SNARE proteins embedded in membranes. J Biol Chem, 292(29), 12165-12177. doi:10.1074/jbc.M116.773523

Zurawski, Z., Rodriguez, S., Hyde, K., Alford, S., \& Hamm, H. E. (2016). Gbetagamma Binds to the Extreme C Terminus of SNAP25 to Mediate the Action of Gi/o-Coupled G ProteinCoupled Receptors. Mol Pharmacol, 89(1), 75-83. doi:10.1124/mol.115.101600 


\section{Figure Legends}

Figure 1. A second mutation in addition to G203R was identified in our previously described Gnao1 mutant mouse model. (A) Genomic map around exon 6 showing the location of primers used for genotyping, the G203 codon, and an Sbfl restriction site at the exon 6 splice acceptor site in the WT genomic sequence. (B) Sanger sequencing from a genomic PCR fragment around the G203R mutation in a heterozygous Gnao1 mutant mouse (Feng et al., 2019). The expected G203R codon change (GGG > CGC) and an introduced Sacll site are shown. An unexpected (heterozygous) sequence change (AGG > AAA) eliminates the Sbfl site and also mutates the exon 6 splice acceptor sequence. A genomic (C) and mRNA (D) map of primers to assess splicing in RNA from brains of Gnao1 mutant mice. (E) RT-PCR from cortex or cerebellum tissue of WT (gel lanes labelled G) and mutant (gel lanes labelled R) samples. A band of the expected size of 218 bp was seen for the RT-PCR product for the primers Ex 5 primer and Ex 6 primer. Sanger sequencing did not show any evidence of the G203R mutation in the spliced RNA product indicating that only the WT allele was appropriately spliced. (F) On a $2.5 \%$ agarose gel, a minor product of about 250 bp was observed only in Gnoa1 mutant mice. This is likely due to utilization of a weak splice acceptor site upstream of the usual Exon 6 splice acceptor but there was not sufficient product to show up with the G203R sequence in the Sanger traces. (G) RT-PCR using primers in Exons 5 and 7 showed only the expected band (397 bp) for the Exon 5+6+7 product with no evidence of a product with a skip over Exon 6 to splice Exon 5 and 7 directly. 
Figure 2. Gnao1 mice showed a significant decrease in Ga。 protein expression but normal

G $\beta$ expression level. (A, C) Whole brain $G \alpha_{\circ}$ expression levels were about $50 \%$ of WT in mutant Gnao1 mouse brain lysates. (B, D) This reduction in expression was most significant in cerebellum (CERE), cortex (CTX), hippocampus (HIP) and striatum (STR), while expression was not significantly reduced in brain stem (BS) and olfactory bulb (OB). All expression levels were normalized to that of WT. Unpaired Student's t-test; WT $(n=8)$, Gnao1 $(n=8) ;{ }^{* * * *} p<0.0001$, ${ }^{*} p<0.05$. (E) A representative gel shows the $G \beta$ protein expression patterns in each individual brain region. (F) Quantification of $G \beta$ protein expression levels is unchanged in Gnao1 mice brain lysates comparing to those of their WT siblings. Unpaired Student's t-test; WT ( $n=4)$, Gnao1 (n=4).

Figure 3. Cerebellar Purkinje cells in brain slices from 4-6 week-old Gnao1 mutant mice display reduced GABAergic spontaneous synaptic currents (sIPSCs) and reduced miniature synaptic currents (mIPSCs). (A, B) Representative recording of spontaneous inhibitory postsynaptic currents in a cerebellar Purkinje cell from a 4 week-old mouse in the presence of $10 \mu \mathrm{M}$ of CNQX and $100 \mu \mathrm{M}$ of AP-V at a holding potential of $-70 \mathrm{mV}$. (C) Gnao1 mice showed a decrease in the frequency of sIPSCs. (D) No significant difference is observed in the amplitude of sIPSCs between WT and Gnao1 mice. Unpaired Student's t-test; ${ }^{* *} p=0.0086$ WT ( $n=13$ mice), Gnao1 ( $n=9$ mice). (E, F) Representative recording of spontaneous miniature inhibitory postsynaptic currents in a cerebellar Purkinje cell from a 4 week-old mouse in the presence of $10 \mu \mathrm{M}$ of CNQX, $100 \mu \mathrm{M}$ of AP-V and $0.5 \mu \mathrm{M}$ TTX at a holding potential of $-70 \mathrm{mV}$. 
(G) Gnao1 mice showed a decrease in the frequency of mIPSCs. (H) No significant difference is observed in the amplitude of mIPSCs between WT and Gnao1 mice. Unpaired Student's ttest; ${ }^{* *} p=0.0011 ;$ WT ( $n=13$ mice), Gnao1 ( $n=9$ mice). Recordings from each cell are shown as a data point but the bar graph, error bars, and statistical analysis was averaged data per animal. Data were recorded from 25 cells of 13 WT mice for WT and 21 cells from 9 Gnao1 mice.

Figure 4. Gnao1 mutant slices show no difference in either sEPSCs or mEPSCs. (A) sEPCSs were recorded from Purkinje cells at a holding potential of $-70 \mathrm{mV}$ in the presence of 10 $\mu \mathrm{M}$ bicuculline. (B) $0.5 \mu \mathrm{M}$ TTX was then added to the bath in order to record mEPSCs. (C, E) No significant difference in either frequency or amplitude was observed between WT and Gnao1 mice. (D, F) No significant difference between WT and Gnao1 mice was observed in mEPSCs either. Unpaired Student's t-test; WT $(n=5)$, Gnao1 $(n=5)$. Data were recorded from 11 cells of 5 WT mice for WT and 6 cells from 5 Gnao1 mice.

Figure 5. A selective inhibitor of $G_{i / o}$, PTX, increased the frequency of mIPSCs in Gnao1 but not WT mice. Slices were incubated in $1 \mu \mathrm{M} / \mathrm{ml}$ of PTX for $>6 \mathrm{hrs}$ pre-recording. Representative traces showed the example recordings of (A) sIPSCs in WT and Gnao1 mice before and after PTX incubation. (B, D) PTX incubation significantly relived the $G_{0}$ mediated inhibition of mIPSC frequency in Gnao1 mice, but not WT mice. Unpaired Student's t-test; WT ( $n=5$ mice), Gnao1 ( $n=6$ mice); ${ }^{* *} p=0.006$. (C, E) PTX did not change the mIPSC amplitude of either Gnao1 or WT mice. Data were recorded from 11 cells of 5 WT mice and 12 cells from 6 Gnao1 mice. 
Figure 6. Activating $\mathrm{GABA}_{B}$ receptor with baclofen reduces mIPSC frequency but not amplitude. Representative traces showing the reduced mIPSC responses before and after adding baclofen $(10 \mu \mathrm{M})$ in WT $(\mathrm{A})$ and Gnao1 (B) mice w/o baclofen. (C, E, G) Baclofen significantly decreased the frequency of mIPSC and the difference between WT and Gnao1 remains though baclofen was present. Unpaired Student's t-test; WT (n=6), Gnao1 (n=6); ${ }^{* * * *} p<0.001,{ }^{* * *} p=0.003,{ }^{*} p=0.029$ (WT vs. Gnao1), ${ }^{*} p=0.014$ (Gnao1 w/o baclofen). (D, F, H) Amplitude remained unchanged regardless of the existence of baclofen.

Figure 7. Baclofen dose-response curves of WT and Gnao1 are similar to each other. Representative traces showing the mIPSC recording with no baclofen (a), $1 \mu \mathrm{M}$ baclofen (b), 3 $\mu \mathrm{M}$ baclofen (c), $10 \mu \mathrm{M}$ baclofen $(\mathrm{d})$ in WT (A) and Gnao1 (B) mice. Bar graph of mIPSC frequency (C) and amplitude (D) w/o baclofen with WT and Gnao1 mice showed similar trend of baclofen-induced inhibition of mIPSC frequency but not amplitude. Each data point was normalized to the baseline level (no baclofen), and there was no significant dose-response curve shift in either frequency (E) or amplitude (F). WT $(n=10)$, Gnao1 $(n=8)$.

Figure 8. Pre-treatment of CGP36216 $(100 \mu \mathrm{M})$ abolished baclofen $(10 \mu \mathrm{M})$ - induced inhibition of mIPSC frequency. Representative traces showing no significant difference between baseline mIPSC levels (a) of WT and Gnao1 with CGP36216 (b; $100 \mu \mathrm{M})$ and baclofen

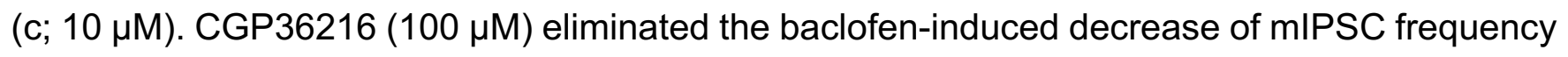
in both WT and Gnao1 (C). Amplitudes remained unchanged despite the drug treatment (D). WT $(n=7)$, Gnao1 $(n=7)$. 
Figure 9. Gnao1 mutants have a modest reduction in molecular layer interneuron count.

(A) Representative immunofluorescent images of WT Kit-eGFP and Gnao1 mutant x Kit-eGFP cerebellar cortex, lobe III. (B,C) Gnao1 mutant mice have significantly fewer but not smaller molecular layer interneurons than WT. Unpaired Student's t-test; WT $(n=5)$, Gnao1 $(n=7)$; ${ }^{*} p=0.027$ (count). (D) No significant difference in the distribution of cells between the upper and lower molecular layers was observed between WT and Gnao1 mutant mice, suggesting a normal distribution of stellate and basket cells in mutants.

Figure 10. Model of $G \alpha_{0}$ loss-of-function in suppression of inhibitory neurotransmitter release.

Mangmool, S., \& Kurose, H. (2011). G(i/o) protein-dependent and -independent actions of Pertussis Toxin (PTX). Toxins (Basel), 3(7), 884-899. doi:10.3390/toxins3070884 
bioRxiv preprint doi: https://doi.org/10.1101/2021.09.23.461583; this version posted September 24, 2021. The copyright holder for this preprint (which was not certified by peer review) is the author/funder. All rights reserved. No reuse allowed without permission.

\section{Figures}

\section{Figure 1}

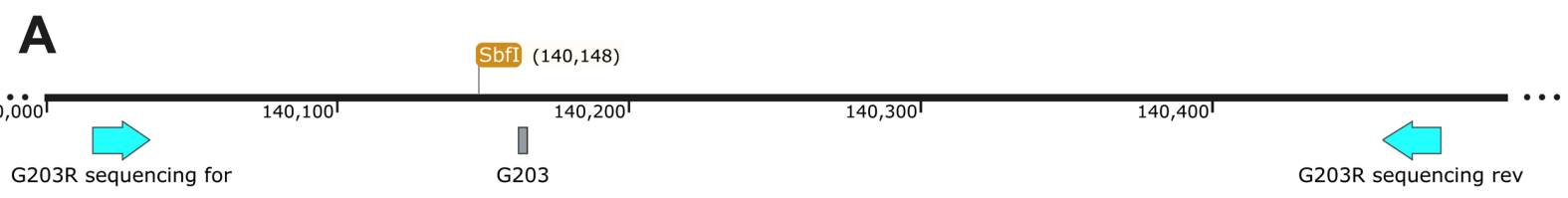

B

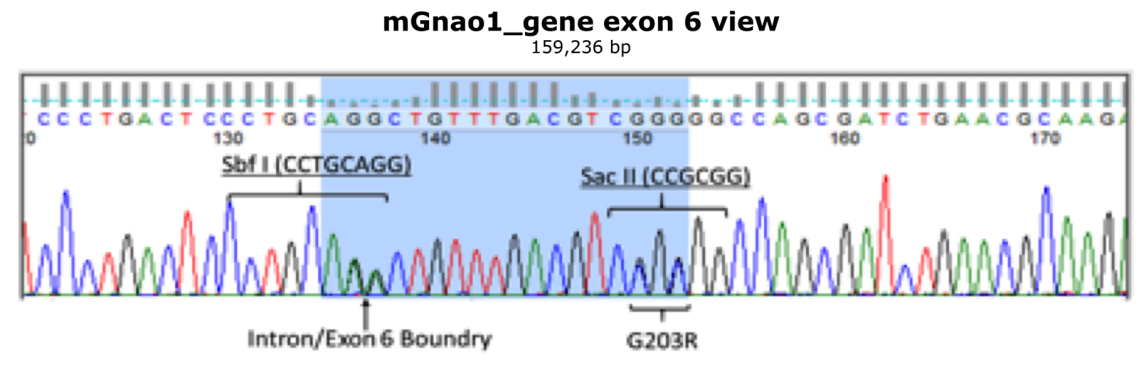

C

Intron/Exon 6 Boundry

SbfI $(144,387)$

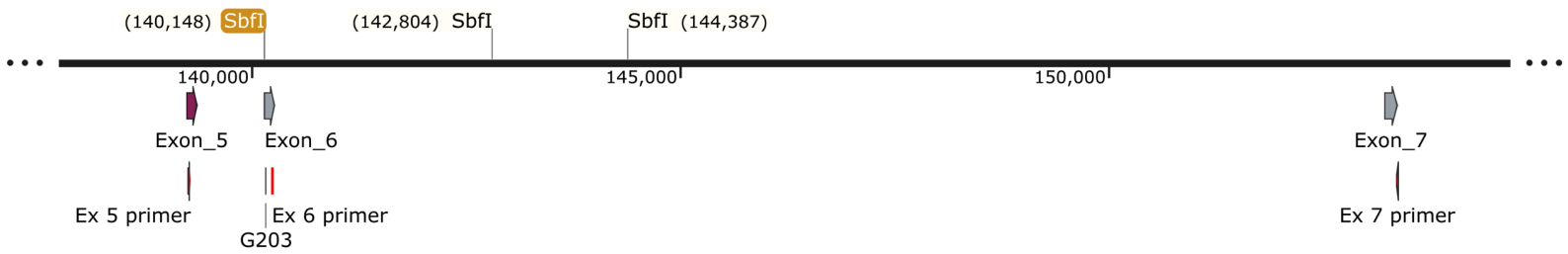

D

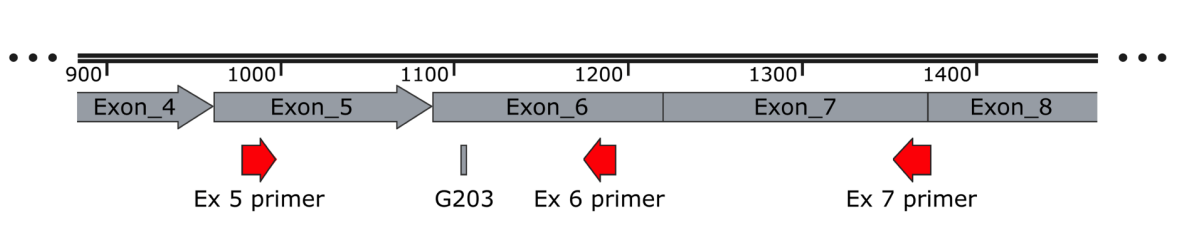

$\mathbf{E}$

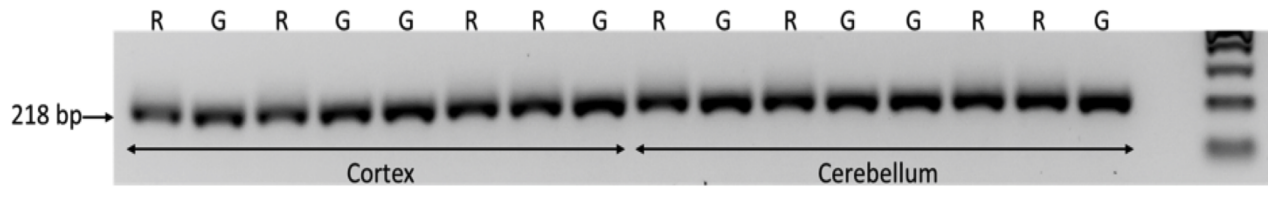

$\mathbf{F}$

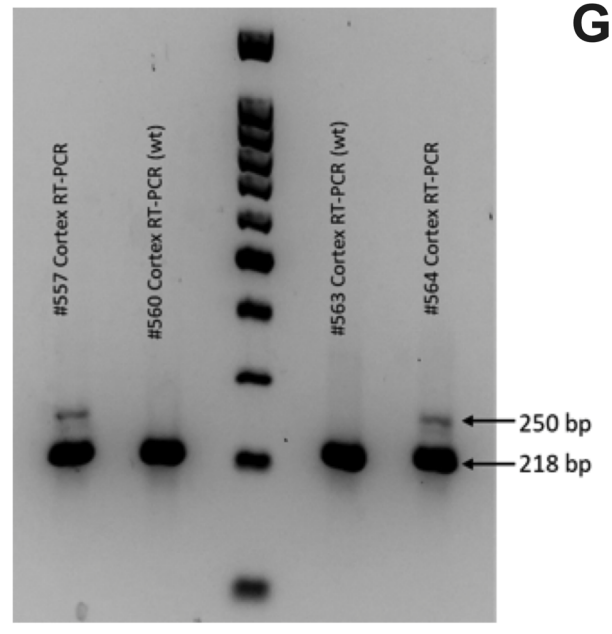

$\mathbf{G}$

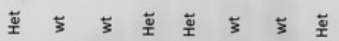


Figure 2

A

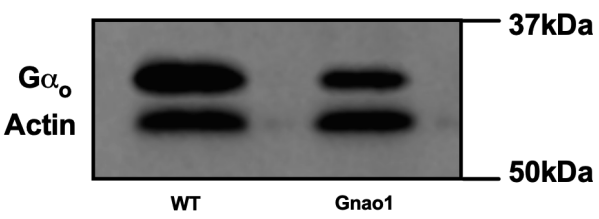

C

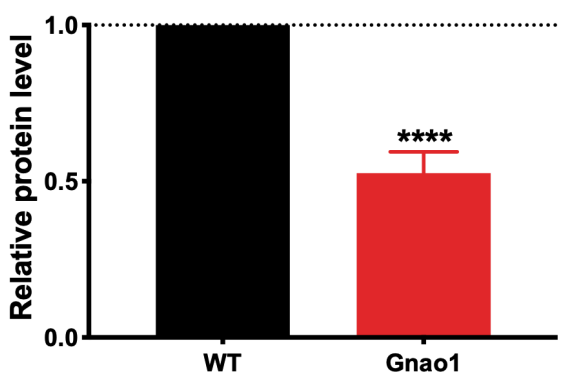

B

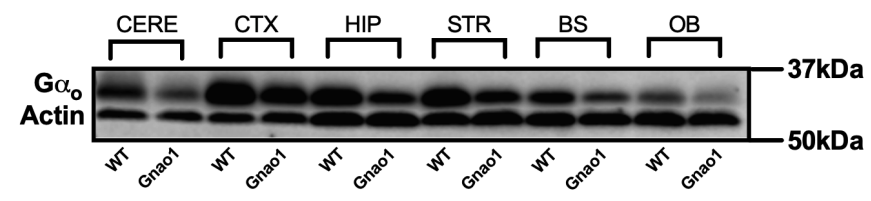

D

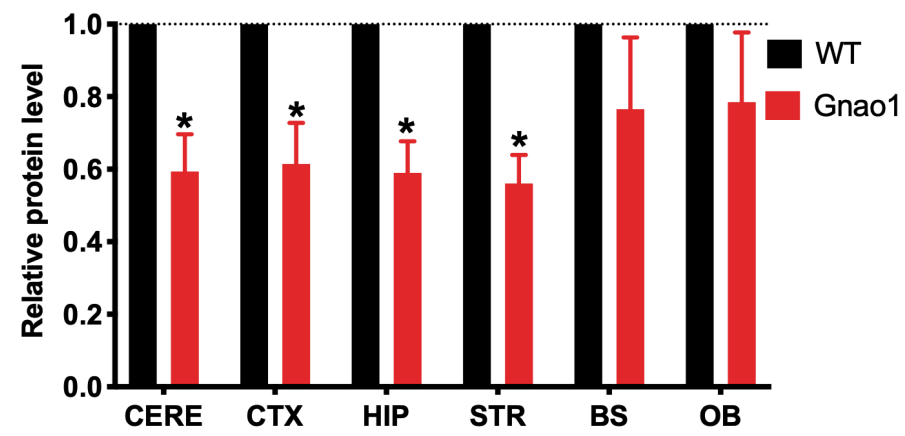

E

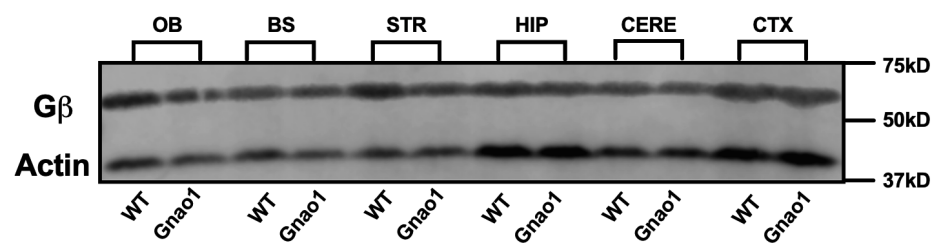

F

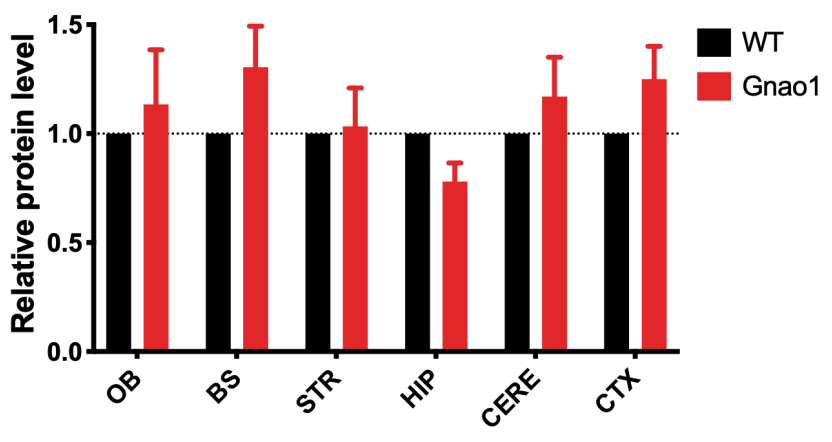


Figure 3

\section{A WT sIPSCs $\quad$ B $\quad$ Gnao1 sIPSCs}

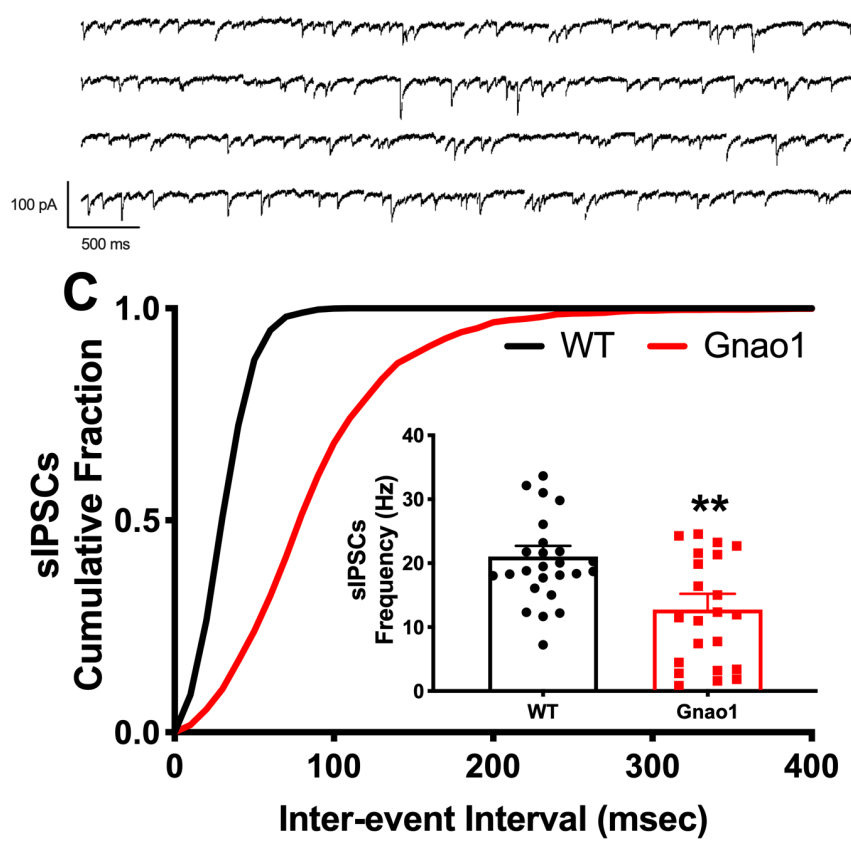

E
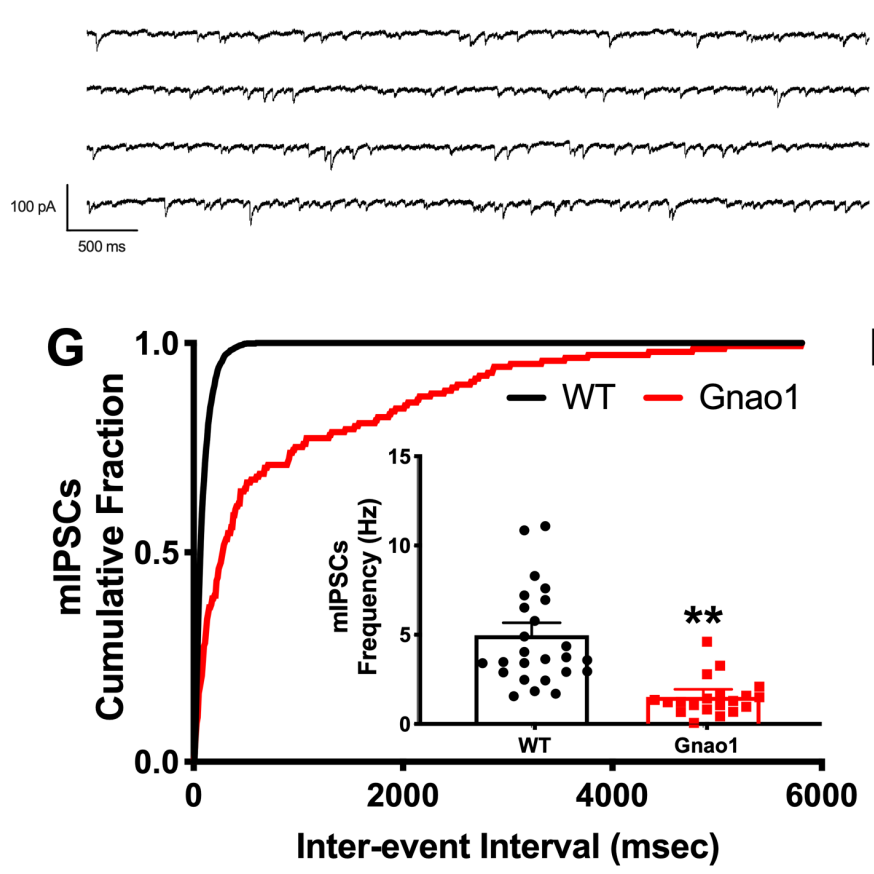

F $\quad$ Gnao1 mIPSCs
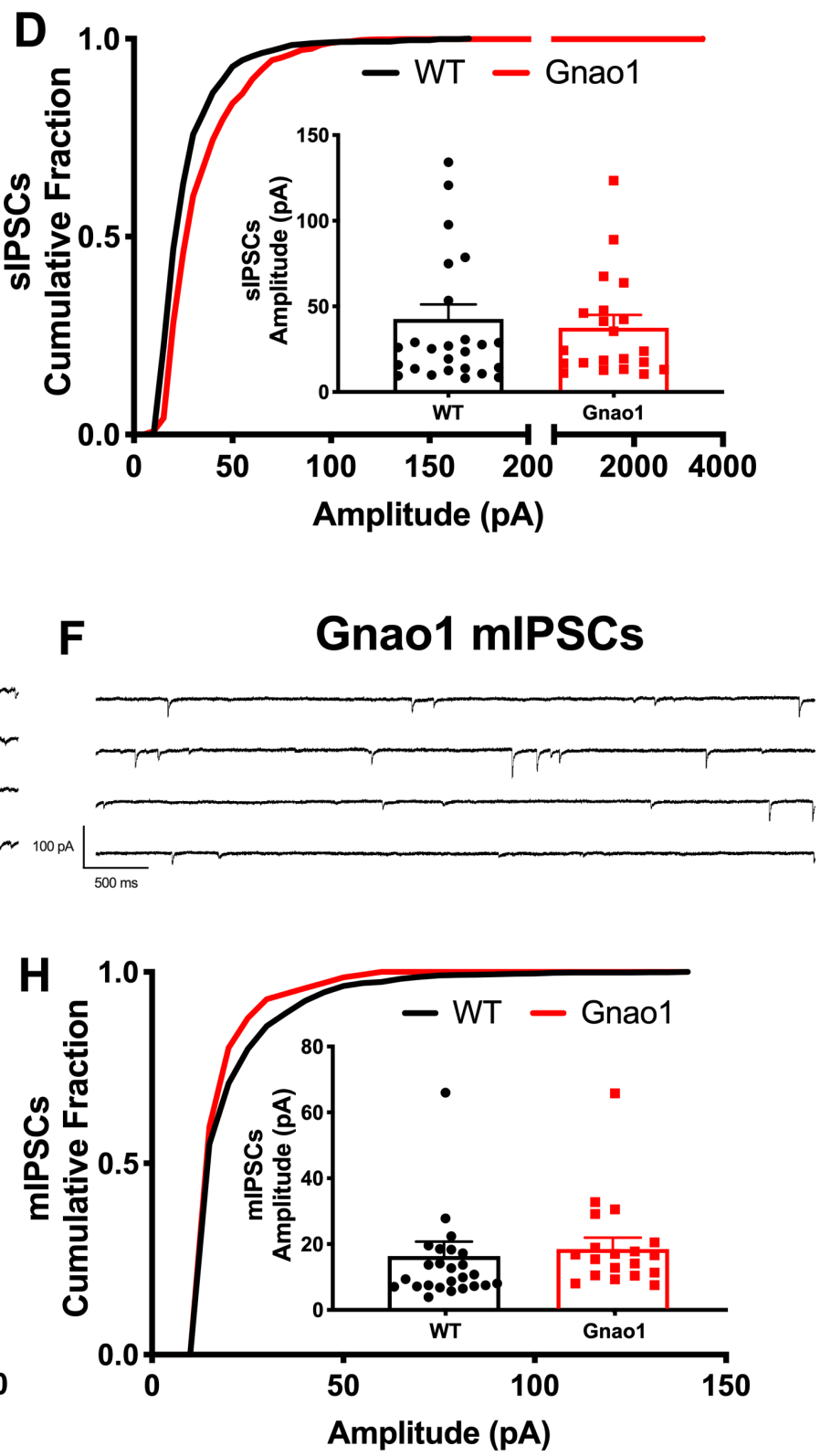
Figure 4
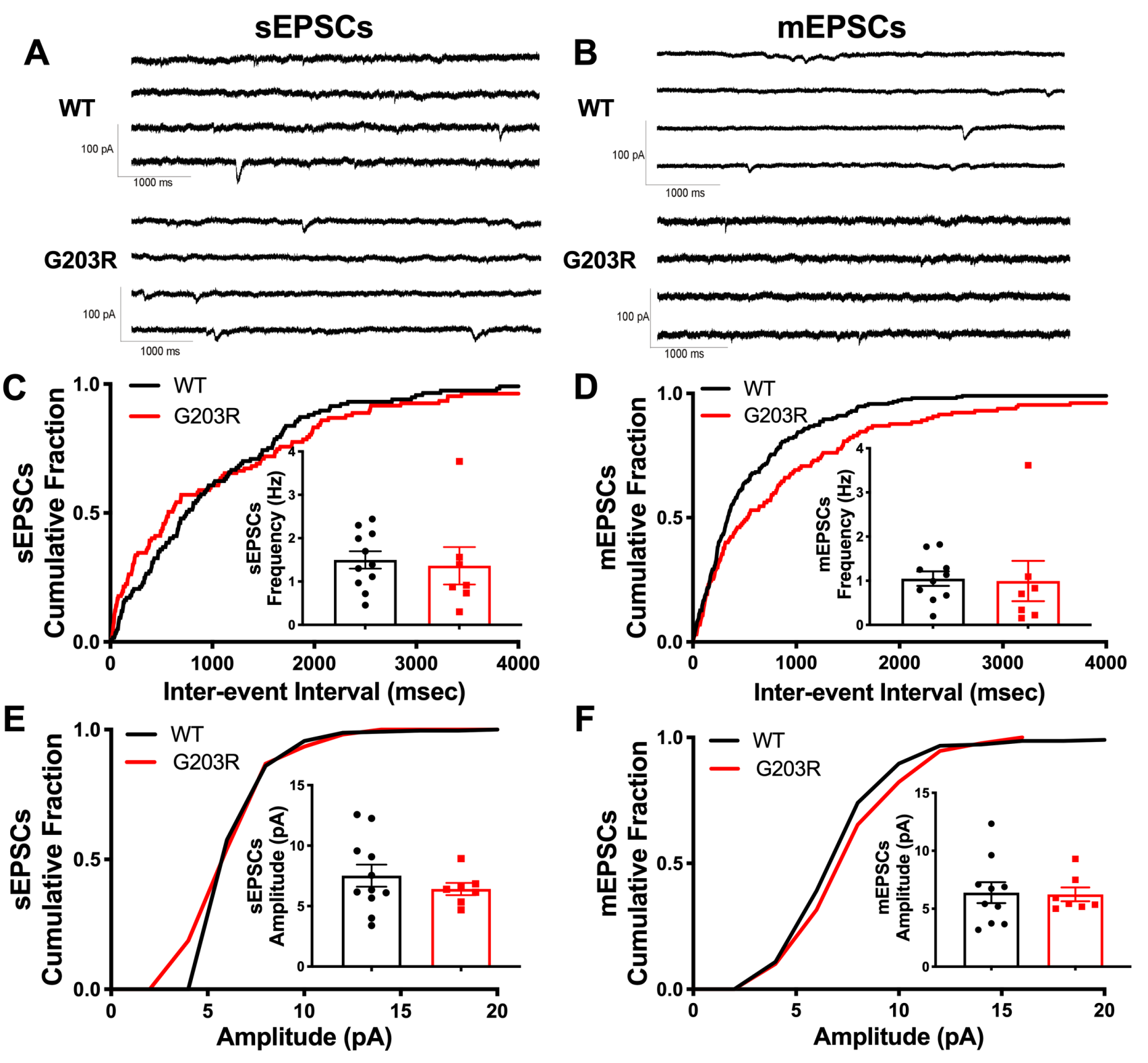


\section{Figure 5}

A a

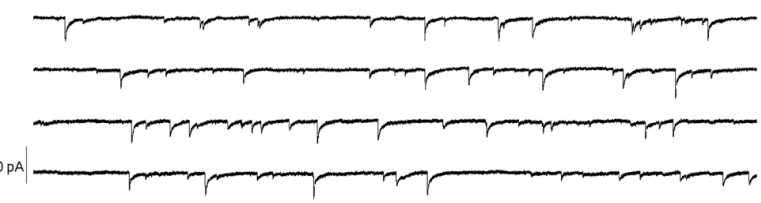

C $\quad$ WT mIPSCs + PTX

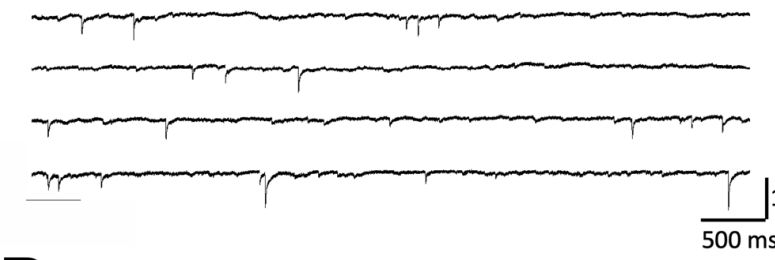

b Gnao1 mIPSCs - PTX
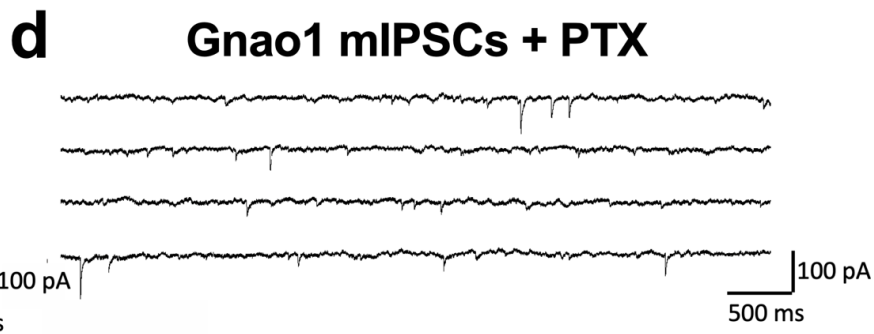

C
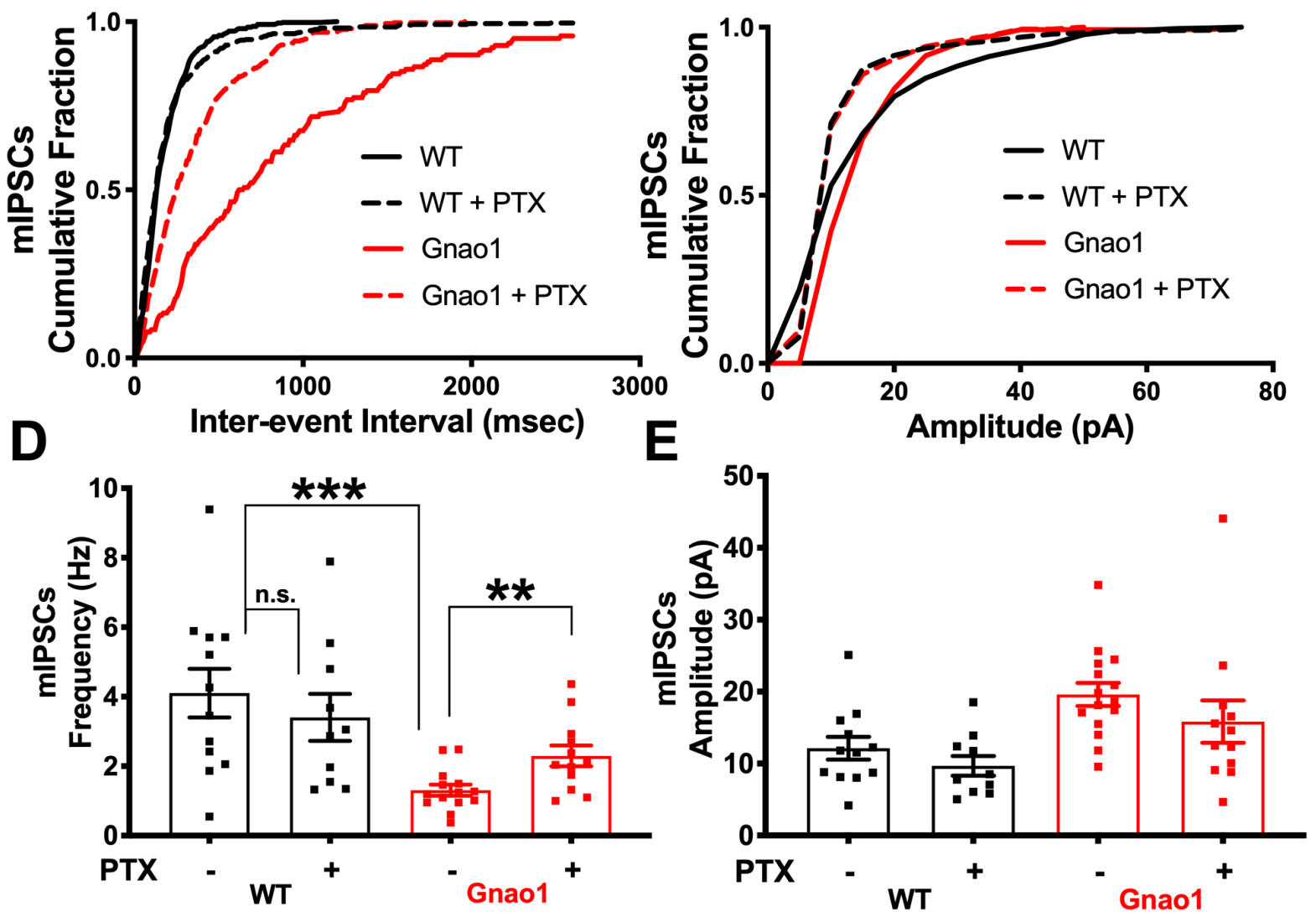


\section{Figure 6}

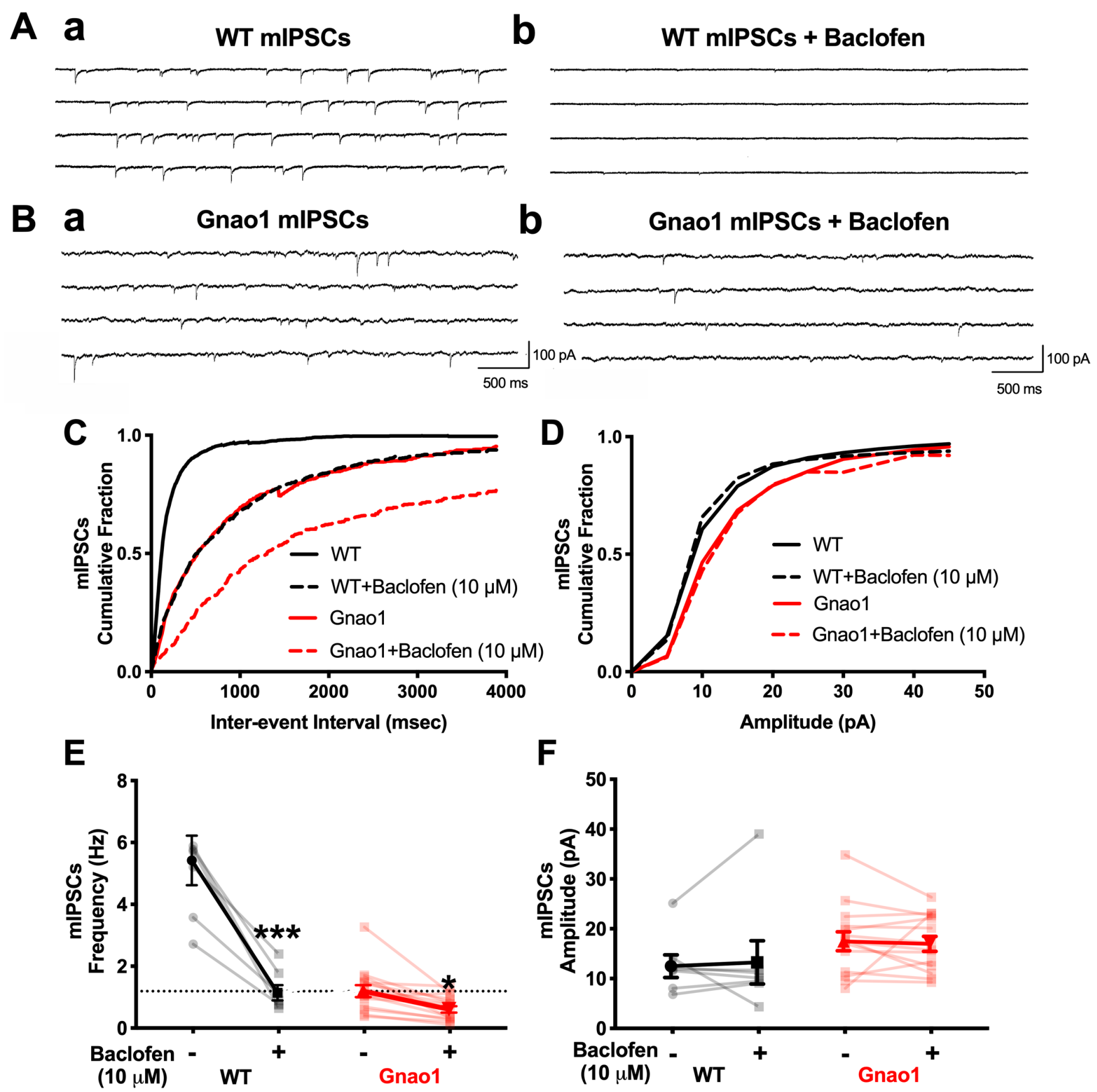


Figure 7






\section{Figure 8}

A a



b

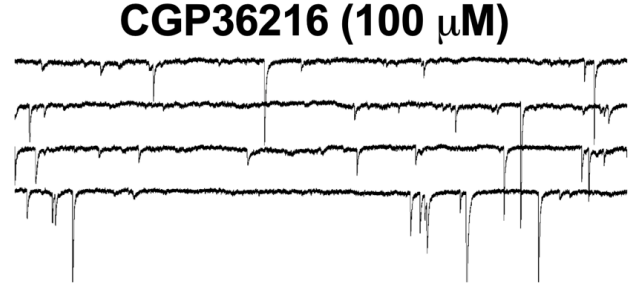

C CGP36216 $(100 \mu \mathrm{M})+$ Baclofen $(10 \mu \mathrm{M})$

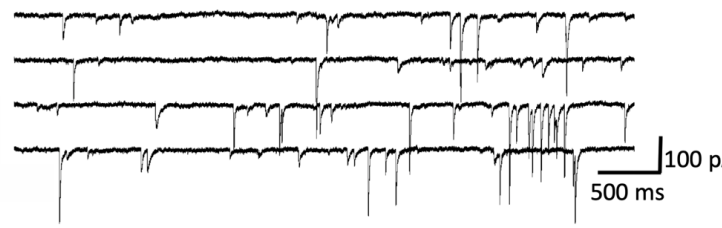

C

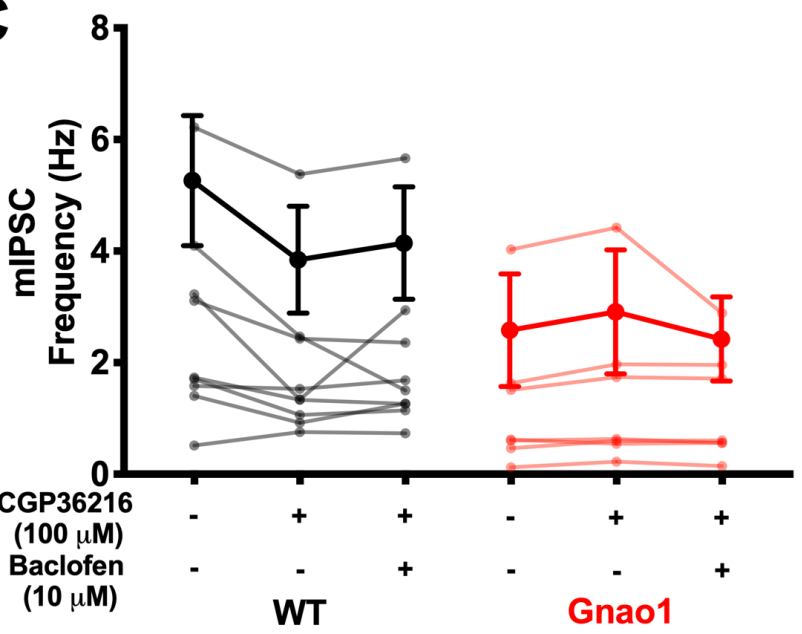

B a

Gnao1 mIPSCs

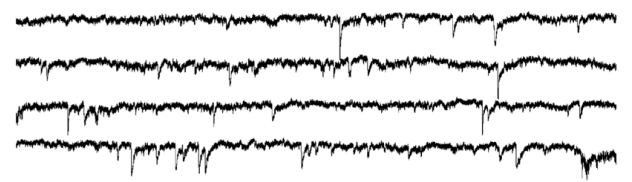

b

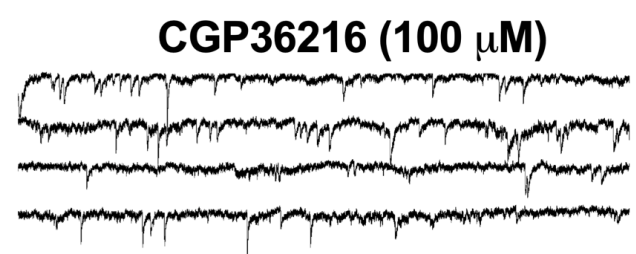

C CGP36216 $(100 \mu \mathrm{M})+$ Baclofen $(10 \mu \mathrm{M})$



D

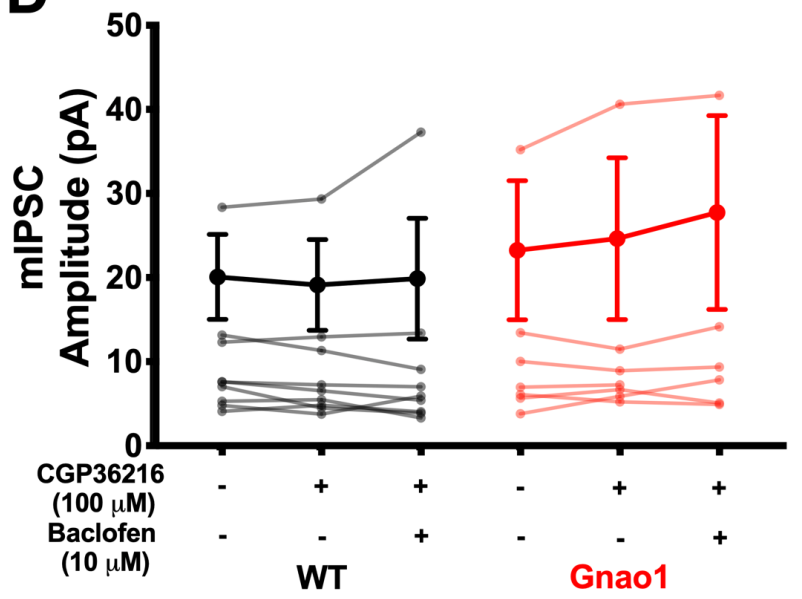


Figure 9
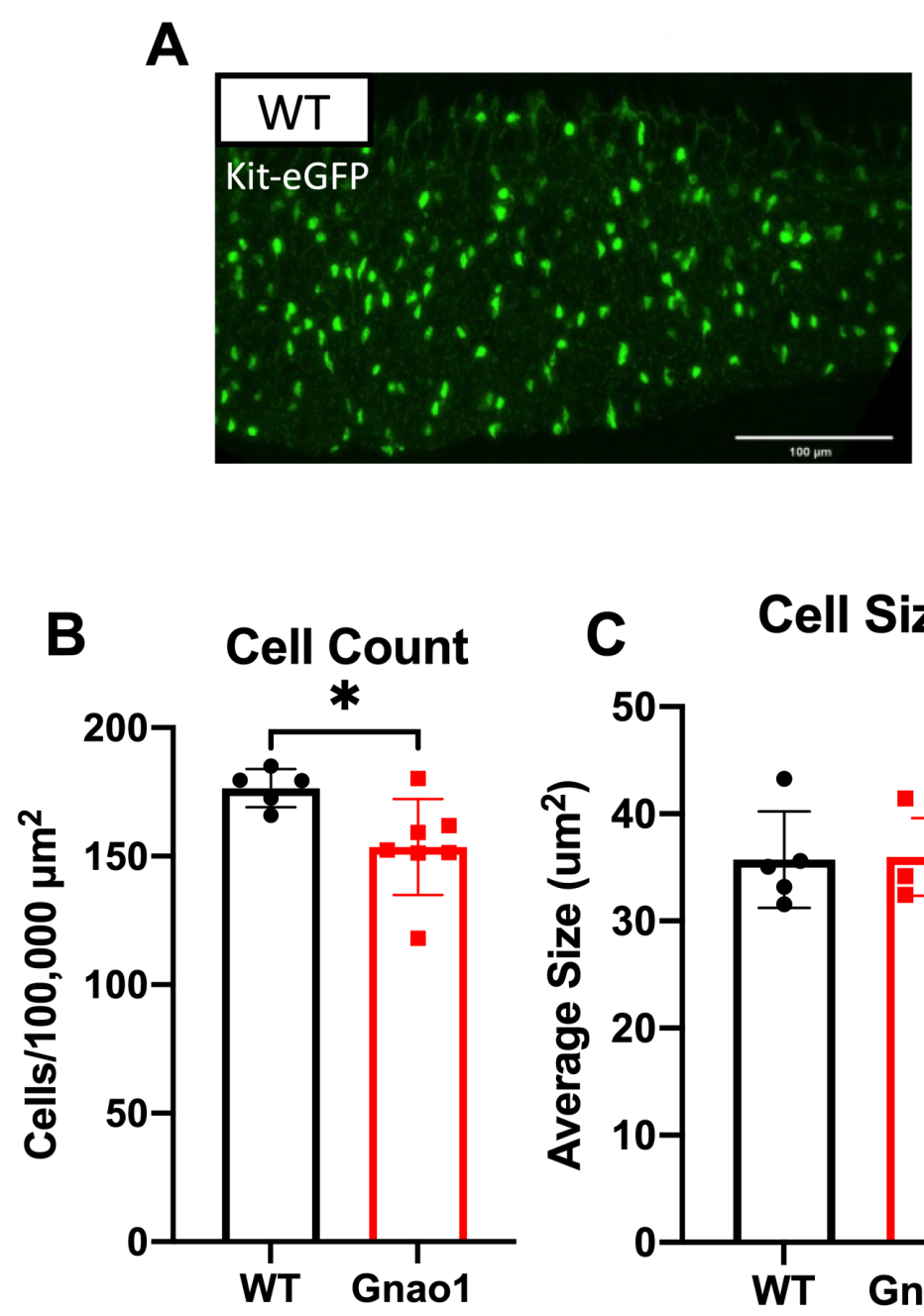

C Cell Size



D Layer Distribution

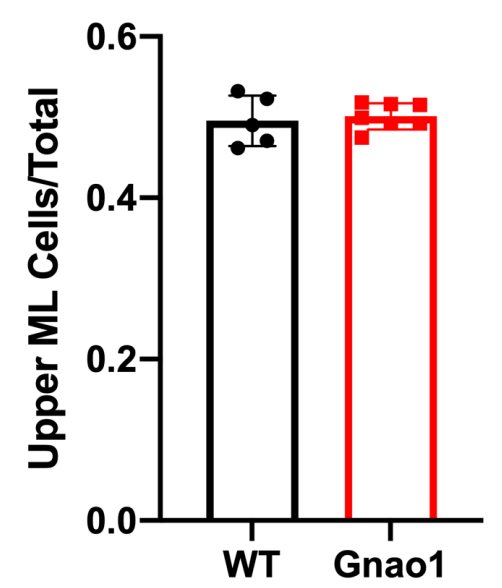


Figure 10

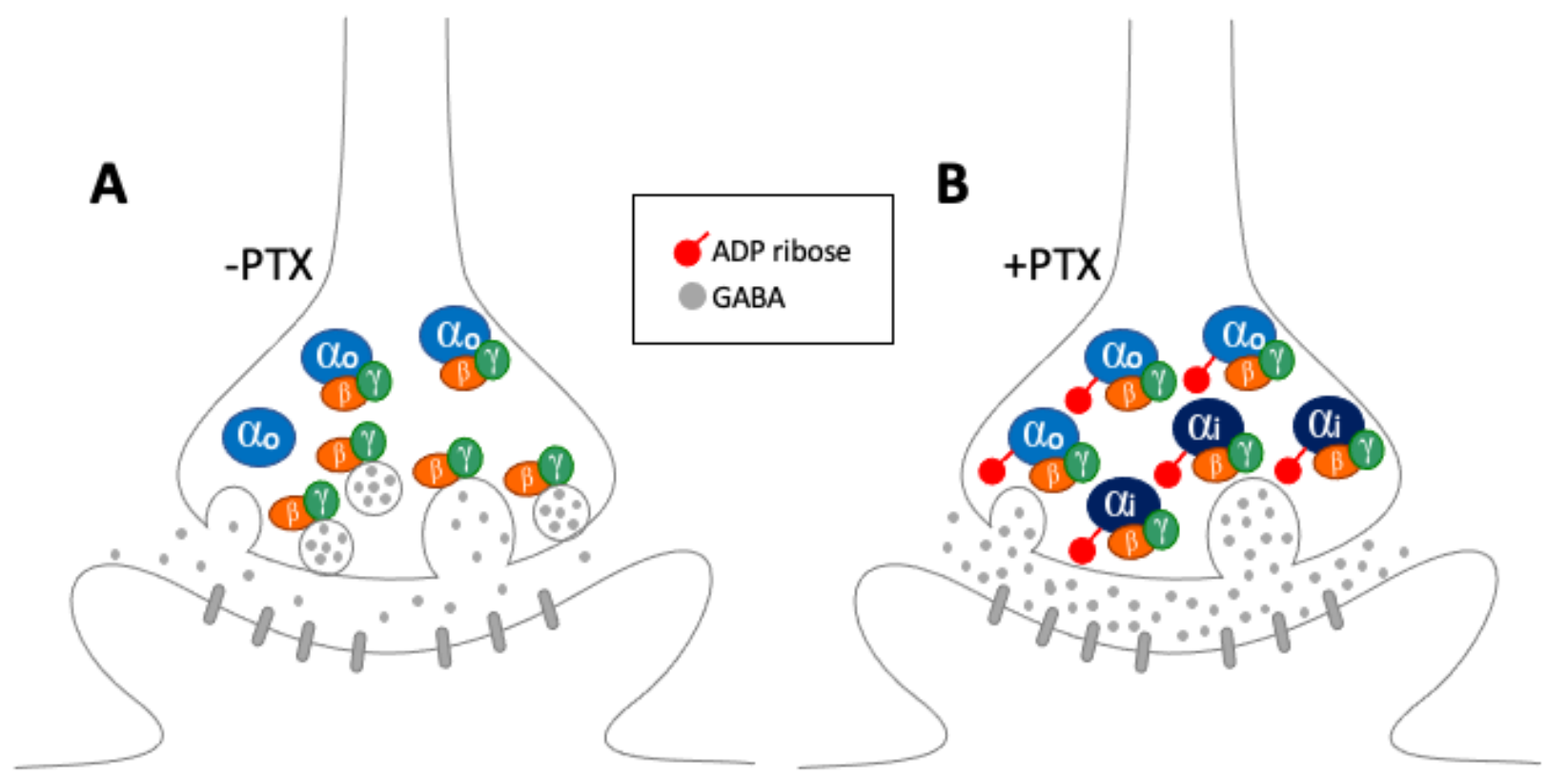

